\title{
A Diáspora: Um Estudo Exploratório sobre 0 Deslocamento Geográfico de Pesquisadores Brasileiros na Década de $90^{*}$
}

\author{
Reinaldo Guimarães
}

"Por que eu, com minha inteligência e talento, fui nascer na Rússia?"

Alexander Puschkin

\section{INTRODUÇÃO}

$\mathrm{E}$ ste trabalho visa estimar a intensidade, a origem, o destino, as motivações gerais e os padrões de retorno dos deslocamentos de longo prazo, nacional e internacional, de pesquisadores brasileiros durante parte da década de 90. A migração de mão-de-obra qualificada no Brasil é, hoje, uma questão em aberto. A bibliografia nacional sobre o assunto é escassa e, no segmento de pesquisadores, registra apenas duas pesquisas abrangentes sobre o tema, ambas realizadas nos anos 70. A primeira foi efetuada sob o patrocínio do Instituto Brasileiro de Relações Internacionais - IBRI e da Escola Brasileira de Administração Pública - EBAP/FGV em 1972 (Schwartzman,

\footnotetext{
* Agradeço a Renato Möller (diretor) e a Fernando Cesar de Castro Bezerra (gerente de projetos) do Programa de Demandas Sociais da Universidade do Estado do Rio de Janeiro - PRODEMAN/UERJ, que executaram o survey contido neste trabalho. Registro a participação de Harvey Faleiro Chaves e Sérgio Jun-Ji Shiguti no trabalho de gerenciamento da base de dados do diretório, no CNPq.
}

DADOS - Revista de Ciências Sociais, Rio de Janeiro, Vol. 45, nº 4, 2002, pp. 705 a 750. 
1972), e a segunda foi parte de um estudo multinacional patrocinado pela UNESCO/ONU em 1974, cujo relatório final é de 1978 (Schwartzman, 1978). Além dessa carência, o presente trabalho justifica-se pelo tempo decorrido entre esses estudos inaugurais e os dias de hoje e pelas profundas transformações na movimentação mundial de mão-de-obra qualificada decorrentes da globalização econômico-financeira.

Os estudos acima citados confirmam empiricamente as reiteradas evidências parciais e jornalísticas de que a migração de pesquisadores brasileiros não é (ou não era) um fenômeno social relevante, quando comparada com a de outros países do Terceiro Mundo, entre outras razões, porque o Brasil historicamente tem sido um receptor de mão-de-obra. Ocorre que, desde os anos 80 , os registros demográficos acusam uma mudança dessa tendência histórica, sendo bem conhecidos e estudados os novos fluxos migratórios de mão-de-obra brasileira pouco qualificada, em particular para o Japão (Sasaki, 1998) e, mais recentemente, para os Estados Unidos. As evidências internacionais existentes sobre a migração de pesquisadores da periferia para os países centrais mostram uma crescente importância do problema, sendo estimado que cerca de 400 mil pesquisadores ${ }^{1}$ oriundos de países em desenvolvimento vivem e trabalham nos EUA, na União Européia UE e no Japão, onde representam cerca de um terço da massa crítica total de pesquisa (Meyer e Brown, 1999). Um outro levantamento, realizado pela National Science Foundation, revela que, em 1993, dos 345 mil doutores engajados em P\&D nos Estados Unidos, 101 mil eram estrangeiros. Destes, $70 \%$ tinham obtido seu doutorado em uma instituição norte-americana (Gwynne, 1999:2).

O termo brain drain foi cunhado após a Segunda Guerra Mundial para denominar a migração de mão-de-obra qualificada da Europa destruída para os Estados Unidos vencedor. Estima-se que, entre 1949 e 1965, quase 100 mil acadêmicos tenham realizado esse trajeto (Teferra, 2000). Durante os anos 50 e 60, a cada ciclo de aparecimento de novos países independentes (em particular na África) ou recém-industrializados (em particular na Ásia e na América Latina), cresciam a preocupação e a bibliografia sobre o problema da migração de cérebros. O já mencionado estudo multicêntrico do início dos anos 70 patrocinado pela UNESCO, muito provavelmente, teve esses ingredientes como combustível. No caso brasileiro, mais especificamente, havia o interesse de avaliar a repercussão da perda de pesquisadores so- 
bre o projeto desenvolvimentista em sua versão autoritária que alavancou a construção do parque científico-tecnológico brasileiro naquele período.

A década seguinte estabeleceu novos caminhos para a política global, com a derrocada da União Soviética, a consolidação da hegemonia norte-americana e o desestímulo à reflexão sobre as grandes assimetrias mundiais em um mundo que se tornava então unipolar. Sob uma óptica econômica, esse período esteve associado também à ascensão das explicações baseadas nas virtudes do livre funcionamento dos mercados, à crise dos sistemas estatais e à decadência do planejamento como ferramenta para o desenvolvimento. Não é de estranhar, portanto, a diminuição do interesse pelo tema nos anos 80 , posto que o brain drain é uma clássica assimetria internacional onde as intervenções exercidas para diminuí-lo haviam sido, até então, marcadas pelo planejamento estatal dos países em desenvolvimento ou por iniciativas de organismos multilaterais.

Ao mesmo tempo que testemunhou a permanência ou mesmo o agravamento da intensidade do fluxo de pesquisadores dos países periféricos para os centrais, a década de 90 vivenciou o aumento exponencial das possibilidades de comunicação entre pessoas em todo o planeta. Além disso, viu aumentar enormemente a importância do conhecimento científico e tecnológico no desenvolvimento dos países. E, finalmente, recolocou o brain drain na geopolítica das relações Norte-Norte (Schuster, 1994). Essas quatro dimensões acabaram por colocar a migração de pesquisadores novamente no centro do debate.

A abordagem atual do problema estabeleceu duas novas características. Em primeiro lugar, procura-se deslocar os pesquisadores migrados de uma posição de "perdidos" para os países doadores, para uma posição de "potencialmente úteis" para os mesmos. Esse deslocamento é sintetizado pela expressão brain gain, em substituição a brain drain. Dessa perspectiva e no plano da formulação de políticas, Meyer sugere o deslocamento de uma política "de retorno" para uma política "de diáspora" (Meyer e Brown, 1999). Em segundo lugar, a passagem do brain drain para o brain gain dar-se-ia usualmente por intermédio de mecanismos descentralizados, não-governamentais e, quase sempre, virtuais. A formação dessas redes virtuais internacionais que estimulam o contato de pesquisadores migrados com seus compatriotas baseados no país de origem tem se multiplicado por todo o mun- 
do (Meyer identificou 41 delas), com resultados promissores, mas ainda a serem avaliados em função de seu pouco tempo de funcionamento. De qualquer forma, são iniciativas importantes, em particular para países que não lograram constituir uma base científico-tecnológica efetiva dentro de suas fronteiras. Todavia, em paralelo a essas experiências, países como Índia, China, Coréia e Cingapura, onde a migração de cientistas é um fato social importante, não deixaram de promover bem-sucedidos programas de repatriamento coordenados pelo Estado, lançando mão de incentivos pessoais diferenciados e de pesados investimentos em infra-estrutura de pesquisa. Vale destacar que as políticas de brain gain através de redes virtuais colaborativas, de modo geral, não permitem a contribuição dos pesquisadores migrados na formação de novos pesquisadores no país de origem (Oni, 2000).

No que se refere à comunidade científica brasileira, um indicador interessante da mudança nos padrões de relacionamento dos nossos pesquisadores com a comunidade científica internacional, no sentido de uma maior integração, foi evidenciado na primeira metade da década de 90 por Meneghini (1996). Estudos mais recentes dão conta dessa mudança entre 1986 e 2000, quando a presença de artigos indexados com endereços brasileiros cresceu $213 \%{ }^{2}$, a presença de artigos com endereços exclusivamente brasileiros aumentou $166 \%$ e a presença de artigos com endereços brasileiros e estrangeiros cresceu $627 \%$ (Guimarães et alii, 2001a). No que interessa ao nosso tema, poderíamos interpretar esse crescimento exponencial de co-autorias entre pesquisadores brasileiros e estrangeiros como parte de um fenômeno mais amplo de internacionalização que poderia incluir também um aumento na taxa de saída de pesquisadores brasileiros para o exterior.

A desigualdade é o traço social mais característico do nosso país, e uma de suas manifestações mais evidentes são as assimetrias regionais. Presentes em praticamente todos os aspectos da vida social, no terreno científico-tecnológico assumem, talvez, uma de suas situações mais críticas. Muito embora nenhum país do mundo exiba uma distribuição territorial homogênea de sua capacidade instalada de pesquisa, tudo indica que, no Brasil, com sua histórica e reiterada tradição em concentrar, essa distribuição seja bem mais desigual do que a observada nos países líderes em pesquisa no mundo, pelo menos 
aqueles com dimensão territorial e diversidade cultural comparáveis à nossa.

Ao lado de reconhecer a pertinência e a atualidade do problema da concentração regional da atividade de pesquisa no Brasil, cumpre registrar que, do mesmo modo que no brain drain internacional, a visão que temos da mobilidade interna de pesquisadores é pautada em realidades que talvez não mais subsistam. Assim como nossa percepção atual da migração de cientistas para o exterior é ainda orientada por uma dinâmica demográfica há muito transformada, é possível que nossa percepção da movimentação interna seja também sustentada em alguns pressupostos que não respondem a mudanças sociais ocorridas no país nos últimos trinta ou quarenta anos.

A espinha dorsal desse entendimento trabalha com a imagem de um fluxo migratório de pesquisadores das regiões Nordeste e Norte para o território inventado, creio, por Henfil e denominado de "Sul-maravilha". Imagem provavelmente real ainda nos dias de hoje, mas que deixa de homenagear muitas outras dimensões com prováveis impactos importantes na dinâmica geográfica da mão-de-obra qualificada do país. Por exemplo, o processo de expansão da fronteira agrícola desde o Rio Grande do Sul, através da região Centro-Oeste, chegando ao Norte, teria ficado restrito à migração de trabalhadores rurais ou pequenos proprietários ou, a partir desse componente, teria estabelecido laços societais mais complexos e permanentes com essas regiões, implicando, entre outros aspectos, na mobilidade de pesquisadores entre elas? Da mesma forma, o crescimento desordenado e a epidemia de violência prevalentes nas grandes metrópoles brasileiras - em particular nas duas maiores -, em associação com o crescimento internacional do prestígio das cidades médias como produtoras de melhor "qualidade de vida", poderia estar fazendo com que estas últimas atraíssem pesquisadores. Ou ainda, as repercussões na movimentação de pesquisadores decorrente da intensa descentralização dos programas de pós-graduação na década de 90, ocorrida do Sudeste em direção às regiões Nordeste e Sul (Guimarães et alii, 2001b) poderia estar provocando mobilidade de pesquisadores nessas direções. E, por fim, o processo de declínio econômico e político de algumas grandes cidades, como o que ocorre no Rio de Janeiro desde a mudança da capital para Brasília poderia ser, também, um estímulo à abertura de novas rotas de mobilidade interna. 
Estes são exemplos de fatos relativamente recentes na história social de nosso país capazes de alterar, no sentido de enriquecer ou, no mínimo, tornar mais complexo, o panorama dos deslocamentos internos de pesquisadores. Sinalizam que, do mesmo modo que o brain drain internacional, esta é também uma questão em aberto.

Com o objetivo de contribuir para a atualização do debate sobre a migração de pesquisadores brasileiros, realizamos um survey através da internet a partir dos dados do Diretório dos Grupos de Pesquisa no Brasil em sua versão 4.0, relativa ao ano 2000. Esta pesquisa deve ser apreciada como um exercício exploratório, um esforço de recolocar na ordem do dia um tema que, dados os padrões demográficos brasileiros e a outras características peculiares às nossas política e cultura, foi sempre considerado pouco relevante. Retomá-lo decorre exatamente da alteração daqueles padrões demográficos e da concomitante mudança na inserção internacional e na mobilidade interna dos nossos pesquisadores.

Como se verá mais adiante, entre outubro de 2000 e janeiro de 2001, 2.769 líderes de grupos de pesquisa responderam a um questionário e relataram o afastamento, entre 1993 e 1999, de 2.508 pessoas dos grupos de pesquisa aos quais pertenciam. Os respondentes compõem uma amostra auto-selecionada e não aleatória de 10.055 líderes de grupos para os quais foi enviado o questionário, o que fornece uma taxa de respostas de 27,5\%. A pergunta-chave do questionário não indagava por "migrantes", mas por pessoas que se afastaram para morar em outra unidade da federação - UF ou outro país ${ }^{3}$. Essa decisão nos pareceu ampliar o escopo dos afastamentos percebidos e permitiu analisar também aqueles que já haviam retornado ao final do período de observação. Portanto, neste trabalho, os 2.508 indivíduos que se afastaram da sua UF ou do país no período de referência serão denominados "afastados", e o seu movimento será denominado "afastamento". Aos componentes do subconjunto destas que, ao final do período de referência, não haviam voltado e que, provavelmente, não voltarão, denominamos "migrados" e ao seu movimento, "migração".

Uma outra observação importante diz respeito ao perfil dos indivíduos cujo afastamento foi relatado. Embora os chamemos genericamente de "pesquisadores", à época em que seus afastamentos ocorre- 
ram nem todos eram, na verdade, formados e ativos. Há entre eles um grande número de pesquisadores em formação cujo motivo do afastamento, como se verá, foi a realização de um doutorado. Portanto, a definição dos "pesquisadores" afastados foi realizada pelos respondentes, líderes de grupos de pesquisa, estes sim pesquisadores ativos. De qualquer modo, pode-se afirmar com segurança que os afastamentos relatados disseram respeito a indivíduos que eram pesquisadores formados ou em formação, todos no entanto com algum envolvimento com a atividade de pesquisa.

\section{METODOLOGIA}

Nos seus quatro primeiros anos de existência, a internet alcançou cinqüenta milhões de usuários. O tempo levado para a televisão alcançar este número foram treze anos e para o rádio, 38 anos. Estima-se, para o ano 2005, que um bilhão de pessoas estejam ligadas na rede (Department of Commerce, 1998). Esse crescimento exponencial, entre outras conseqüências, habilitou-a a tornar-se uma importante ferramenta para a realização de surveys dos mais variados tipos. As primeiras utilizações da internet com essa finalidade vieram de empresas, com o objetivo de estabelecer perfis de seus próprios empregados e, mais tarde, de seus clientes.

O primeiro survey eletrônico relatado pela literatura, realizado através de e-mails em um ambiente de rede local, foi realizado nos Estados Unidos em 1986 e teve como alvo os empregados de uma firma comercial (Kiesler e Sproull, 1986). Mais tarde, os surveys eletrônicos passaram a ser utilizados também com finalidades de pesquisa acadêmica. Os dois tipos mais comuns de surveys eletrônicos são os realizados através de correio eletrônico e os que lançam mão da world wide web (www). No primeiro, enviam-se questionários anexos a mensagens e aguardam-se respostas do mesmo modo; no segundo, os respondentes têm acesso a uma página que contém um questionário. Há casos, como o da nossa pesquisa, em que as duas técnicas são utilizadas. Uma mensagem é enviada e orienta o respondente para uma página específica.

Existe hoje uma vasta literatura de avaliação da eficiência, custo, fidedignidade, vantagens, desvantagens e outras características desse procedimento. A consulta a algumas das revisões mais recentes do tema, em resumo, mostra o que se segue: 
(1) As maiores vantagens dos surveys que utilizam a internet são a velocidade e o custo. Quanto à velocidade, estimativas mostram que o tempo de resposta de um survey por e-mail é cerca de $40 \%$ menor quando comparado com o do correio (Sheehan e McMillan, 1999). As avaliações quanto às diferenças de custo são marcantes. Sheehan e Hoy (1999) realizaram um estudo controlado em que comparam um survey via correio com uma pesquisa similar utilizando e-mails. Para uma amostra de 5 mil indivíduos, o custo do primeiro foi de US\$ 6,5 mil, enquanto o do segundo foi de US\$ 470 .

(2) Os maiores problemas colocados pelos surveys eletrônicos dizem respeito à definição e representatividade das amostras, bem como às taxas de respostas. Auto-seleção, respostas múltiplas, desconhecimento do universo potencial dos respondentes, associados a altas taxas de não-respostas, têm lançado algumas sombras sobre a eficiência dessa metodologia. Além disso, verificações empíricas têm demonstrado que as taxas médias de respostas a surveys eletrônicos vêm diminuindo nos Estados Unidos, provavelmente em conseqüência da saturação da população (Sheehan, 2001).

Neste artigo, alguns dos principais problemas quanto à representatividade da população e dos respondentes foram contornados em função de termos uma população fechada, conhecida e delimitada ex ante. Além disso, utilizamos a técnica de "amostragem de saturação", que consiste em enviar o instrumento de coleta de dados a todos os componentes da população-alvo (Bradley, 1999).

Em geral, a bibliografia disponível sobre surveys eletrônicos aponta para altas taxas de não-respostas e "negocia" estas altas taxas com a ocorrência de um número grande de respostas dado o custo relativamente baixo da operação de entrevistas. De qualquer modo, uma das maneiras de testar a representatividade da amostra é cotejar algumas características conhecidas e relevantes do universo pesquisado com as correspondentes características dos respondentes. Esta operação foi realizada e não foram identificadas diferenças relevantes entre o perfil dos respondentes e aquele do universo de líderes de grupos de pesquisa quanto a sexo, idade, região geográfica, unidade da federação, instituição e grande área do conhecimento. No entanto, cabe comentar que os respondentes são ligeiramente mais jovens do que o universo de líderes. Os respondentes até 44 anos de idade perfazem $37,0 \%$ do total, enquanto o universo de líderes na mesma faixa res- 
ponde por $40,0 \%$ do total. Entre 45 e 54 anos, a proporção de respondentes e do universo de líderes equivale, respectivamente, a $42,2 \%$ e a $41,8 \%$. Acima de 55 anos de idade, as proporções se invertem, com $18,0 \%$ para os respondentes contra $20,1 \%$ do universo de líderes. No que se refere ao mapa geográfico das respostas, a região Sudeste ficou ligeiramente sobre-representada entre os respondentes ( $59,0 \%$ contra $56,2 \%)$ e as regiões Nordeste e Centro-Oeste um tanto sub-representadas (17,9\% contra 20,6\%). Segundo as unidades da federação, São Paulo e Minas Gerais ficaram algo sobre-representadas, enquanto Pernambuco e o Distrito Federal sub-representadas. Dentre as 224 instituições cujos líderes foram convidados a participar da pesquisa, de 23 - todas instituições de pequeno porte ou universidades privadas sem maior tradição de pesquisa - não obtivemos respostas de nenhum líder. Na distribuição dos respondentes segundo as grandes áreas do conhecimento, observou-se uma muito ligeira sobre-representação das engenharias (17,6\% contra 15,6\%) e das ciências biológicas $(16,3 \%$ contra $14,8 \%)$. Por outro lado, foi observada uma também pequena sub-representação das ciências da saúde (14,3\% contra $15,0 \%)$ e das ciências sociais aplicadas (6,3\% contra $7,8 \%)$. Não somente as diferenças de perfil detectadas entre respondentes e o universo de líderes são muito tênues, como também não permitem estabelecer uma tendência geral que comporte uma explicação substantiva. No entanto, em uma perspectiva muito rigorosa, poder-se-ia sugerir que os líderes mais jovens localizados no Sudeste estão mais presentes nas respostas do que os líderes mais velhos localizados em regiões de "periferia geográfica".

Embora o perfil de respondentes e não-respondentes seja muito parecido, segundo as várias dimensões testadas, um outro aspecto necessitou ainda ser avaliado. Trata-se da hipótese de que o impulso de responder ao questionário estivesse diretamente associado à intensidade da experiência dos líderes de grupo com afastamentos. Em outras palavras, a hipótese é que quanto maior essa experiência, maior o impulso para responder e, como conseqüência, a freqüência de afastamentos observados pelos respondentes fosse maior do que a que seria verificada entre os que não responderam. A confirmação dessa hipótese resultaria em que as proporções de afastados e de migrantes fossem uma superestimação das proporções reais. Para testá-la, em agosto de 2001, foi enviada uma nova correspondência eletrônica a todos os líderes de grupos de pesquisa que não haviam respondido ao 
questionário original. Nela era solicitado apenas que respondessem à primeira pergunta do questionário original da pesquisa, com um complemento para indicar o ano e o número de afastamentos testemunhados em cada ano. Até o final de setembro de 2001 houve 1.759 respostas, sendo que em $65,6 \%$ delas foi relatado o testemunho de pelo menos um afastamento. Ao contrário do que imaginávamos, a freqüência de afastamentos entre os não-respondentes originais foi maior do que a observada entre os respondentes. As proporções de afastamentos, segundo o ano em que ocorreram, foram similares às dos respondentes, bem como o perfil da distribuição regional da ocorrência de afastamentos. Finalmente, os 1.759 não-respondentes primários que responderam à segunda chamada tiveram uma origem geográfica similar à dos respondentes originais.

Pesquisadores relacionam-se em redes de um tipo denominado genericamente "pequenos mundos" (small worlds), e uma de suas características é proporcionar altos graus de conectividade entre seus componentes (Amaral et alii, 2000; Newmann, 2001). Daí que, em relatos de afastamentos feitos por membros da comunidade científica brasileira, não estaria afastada a possibilidade de testemunhos comuns de um mesmo afastamento. Isto foi objeto de checagem, através da verificação dos nomes dos indivíduos que se afastaram, com o objetivo de detectar repetições. Dentre as 2.508 pessoas que se afastaram, encontramos cinqüenta $(2,0 \%)$ com os nomes repetidos. Destas cinqüenta, em apenas 21 casos $(0,8 \%)$ a origem e o destino do afastado era o mesmo nas duas (dezenove casos) ou três vezes (dois casos) em que o nome apareceu. A freqüência real de repetições deve encontrar-se entre essas duas freqüências $(0,8 \%$ e 2,0\%), haja vista a possibilidade de um mesmo nome repetido, com origens e/ou destinos diferentes, poder significar dois movimentos diversos em momentos distintos. Nesses casos, tratar-se-ia de repetições que não estariam significando dupla contagem. De qualquer modo, são freqüências muito baixas, incapazes de alterar os resultados finais do trabalho.

\section{NÚMEROS GERAIS E PERFIL DOS INFORMANTES E DOS QUE SE AFASTARAM}

Dentre os respondentes, $1.583(57,2 \%)$ declararam não ter testemunhado casos de afastamento de pesquisadores no intervalo de interesse da pesquisa, entre 1993 e 1999. Por outro lado, 1.186 líderes de grupos $(42,8 \%)$ mencionaram um ou mais episódios de afastamento de pes- 
quisadores no período de referência. Destes, 62 relataram ocorrências de afastamento desses profissionais sucedidas no início de 2000, momento não contemplado pela pesquisa. $\mathrm{O}$ número final de líderes que se referiram a afastamento de pesquisadores ficou, então, em 1.124.

A proporção de respondentes que citou afastamento de pesquisadores variou segundo as regiões geográficas dos mesmos: Norte - 51,2\%; Centro-Oeste - 43,1\%; Sudeste - 41,0\%; Nordeste-40,6\%; Sul-37,5\%. Para as UFs, a proporção de respondentes que tratou do mesmo tema variou de 76,2\%, no Rio Grande do Norte, a 23,1\%, no Maranhão ${ }^{4}$.

Os 1.124 respondentes que fizeram referência ao afastamento de pesquisadores testemunharam o afastamento de 2.508 pessoas, com uma média de 2,2 afastamentos presenciados por cada líder. Observou-se uma freqüência crescente de saída de pesquisadores do início para o fim do período, conforme os dados da Tabela 1.

Tabela 1

Indivíduos que se Afastaram dos Grupos segundo o Ano do Afastamento

\begin{tabular}{l|c|c}
\hline Ano do Afastamento & № de Afastamentos & $\%$ \\
\hline 1993 & 299 & 11,9 \\
1994 & 220 & 8,8 \\
1995 & 276 & 11,0 \\
1996 & 324 & 12,9 \\
1997 & 328 & 13,1 \\
1998 & 436 & 17,4 \\
1999 & 480 & 19,1 \\
No período, em ano ignorado & 145 & 5,8 \\
\hline Total & $\mathbf{2 . 5 0 8}$ & $\mathbf{1 0 0 , 0}$ \\
\hline
\end{tabular}

Qual a área de atuação dos indivíduos que se afastaram? Com os dados coletados pelo questionário, não é fácil responder a esta pergunta diretamente. O que sabemos é a área de atuação atual do líder do grupo, mas entre esta informação e a que buscamos existem dois ruídos. Em primeiro lugar, nem todos os pesquisadores de um grupo atuam na mesma área do líder. Em segundo, a área do líder, hoje, pode não ser a mesma que na época do afastamento. No entanto, como uma aproximação, assumiremos que a grande área então predominante do grupo do líder indicará a grande área de atuação do indivíduo que migrou, à época da migração. Os dados estão na Tabela 2. 
Tabela 2

Grande Área de Atuação dos Indivíduos que se Afastaram

\begin{tabular}{l|c|c}
\hline Grande Área & № de Afastamentos & $\%$ \\
\hline Ciências Exatas e da Terra & 547 & 21,8 \\
Ciências Biológicas & 525 & 20,9 \\
Engenharias e C. da Computação & 434 & 17,3 \\
Ciências Agrárias & 309 & 12,3 \\
Ciências da Saúde & 284 & 11,3 \\
Ciências Humanas & 238 & 9,5 \\
Ciências Sociais Aplicadas & 121 & 4,8 \\
Letras, Lingüística e Artes & 50 & 2,0 \\
\hline Total & $\mathbf{2 . 5 0 8}$ & $\mathbf{1 0 0 , 0}$ \\
\hline
\end{tabular}

\section{O DESTINO GEOGRÁFICO-INSTITUCIONAL DOS AFASTAMENTOS}

Quanto ao destino dos que se afastaram, 1.359 foram para outra UF e 959 para o exterior. Em 190 casos, os informantes não souberam dizer o destino dos que partiram. Os estados e os países de destino destes encontram-se, respectivamente, nas Tabelas 3 e 4.

No que se refere às instituições de destino, $82,1 \%$ dos afastados para outras UFs encaminharam-se para instituições acadêmicas e institutos de pesquisa: 5,0\% para empresas, 1,5\% para órgãos governamentais e em $11,4 \%$ dos casos, os informantes não souberam precisar a resposta. Entre as instituições de ensino e pesquisa, a USP recebeu 9,7\% dos afastados, seguida pela UNICAMP $(5,4 \%)$, UFSC (3,8\%), UFMG $(2,9 \%)$, UFViçosa $(2,7 \%)$ e UFRJ $(2,6 \%)$. Vinte e duas instituições de ensino e pesquisa receberam a metade de todos os afastados.

Dentre os que foram para o exterior, $72,2 \%$ dirigiram-se para institutos de pesquisa, universidades e hospitais de ensino, 6,4\% para empresas e órgãos de governo e em 21,4\% dos casos o informante não soube precisar a instituição de destino. Ao excluirmos os afastados cujas instituições de destino eram desconhecidas, as porcentagens dos que foram para outra UF ou para o exterior associando-se a uma instituição de ensino ou pesquisa são muito parecidas, perfazendo, respectivamente, $92,7 \%$ e $91,9 \%$.

Embora muitas vezes as atividades de formação e aperfeiçoamento dos pesquisadores estejam imbricadas com seus afazeres profissio- 
A Diáspora: Um Estudo Exploratório sobre o Deslocamento Geográfico...

Tabela 3

Destino dos Afastados segundo a UF de Destino

\begin{tabular}{|c|c|c|}
\hline UF & № de Afastados & $\%$ \\
\hline SP & 365 & 26,9 \\
\hline MG & 147 & 10,8 \\
\hline PR & 122 & 9,0 \\
\hline RJ & 114 & 8,4 \\
\hline SC & 76 & 5,6 \\
\hline RS & 71 & 5,2 \\
\hline DF & 56 & 4,1 \\
\hline BA & 51 & 3,7 \\
\hline GO & 44 & 3,2 \\
\hline PE & 40 & 2,9 \\
\hline $\mathrm{CE}$ & 38 & 2,8 \\
\hline $\mathrm{RN}$ & 38 & 2,8 \\
\hline PA & 31 & 2,3 \\
\hline ES & 25 & 1,8 \\
\hline PB & 21 & 1,5 \\
\hline $\mathrm{AM}$ & 19 & 1,4 \\
\hline MS & 16 & 1,2 \\
\hline SE & 15 & 1,1 \\
\hline MT & 11 & 0,8 \\
\hline $\mathrm{AC}$ & 10 & 0,7 \\
\hline MA & 9 & 0,6 \\
\hline PI & 8 & 0,6 \\
\hline $\mathrm{TO}$ & 8 & 0,6 \\
\hline $\mathrm{AL}$ & 7 & 0,5 \\
\hline $\mathrm{RR}$ & 4 & 0,3 \\
\hline RO & 3 & 0,2 \\
\hline $\mathrm{AP}$ & 2 & 0,1 \\
\hline Ignorado & 8 & 0,6 \\
\hline Total & 1.359 & 99,7 \\
\hline
\end{tabular}


Tabela 4

Destino dos Afastados segundo o País

\begin{tabular}{l|c|c}
\hline País & $\begin{array}{c}\text { № de } \\
\text { Afastados }\end{array}$ & $\%$ \\
\hline Estados Unidos & 413 & 43,1 \\
França & 112 & 11,7 \\
Reino Unido & 111 & 11,6 \\
Outros países europeus & 91 & 9,5 \\
Canadá & 69 & 7,2 \\
Alemanha & 51 & 5,3 \\
América Latina & 40 & 4,2 \\
Espanha & 33 & 3,4 \\
Países asiáticos & 33 & 3,4 \\
Outros países e ignorados & 6 & 0,6 \\
\hline Total & $\mathbf{9 5 9}$ & $\mathbf{1 0 0 , 0}$ \\
\hline
\end{tabular}

nais e vice-versa (treinamento em serviço e serviço no treinamento), para conhecer o perfil dos pesquisadores afastados, foi necessário discriminar os motivos dos afastamentos segundo seu objetivo predominante: (a) complementação da formação acadêmica ou (b) exercício profissional. Desse modo, as razões foram agrupadas em seis categorias: (1) programa de doutoramento; (2) estágio pós-doutoral; (3) outra etapa de formação; (4) atuação profissional não vinculada à etapa específica de formação, inclusive período sabático; (5) motivo acadêmico ou profissional distinto dos anteriores; (6) outros motivos, nem acadêmicos nem profissionais.

As três primeiras opções foram consideradas como objetivos de formação. As opções 4 e 5, objetivos de exercício profissional. A última foi uma alternativa a eventuais afastamentos de pesquisadores cuja motivação houvesse se situado fora das duas situações típicas e que seriam de pouco interesse para a pesquisa (161 afastamentos foram relacionados a esta opção e foram descartados da análise).

Restaram, então, 2.347 afastamentos cujas razões consideramos de interesse. Nesse conjunto, a justificativa mais usual foi a realização de doutorado, com 735 ocorrências (31,3\%). A segunda razão mais freqüente foi "motivo acadêmico ou profissional distinto dos anteriores", com 614 ocorrências $(26,2 \%)$. A terceira razão mais citada foi 
"atuação profissional não vinculada à etapa específica de formação, inclusive período sabático", com 478 ocorrências (20,4\%). Discriminando os afastamentos segundo as duas categorias mais gerais - trabalho e exercício profissional -, foram declarados 1.255 afastamentos $(53,5 \%)$ sob a rubrica "formação" e $1.092(46,5 \%)$ sob a rubrica "exercício profissional".

As razões do afastamento variam segundo o destino do afastado, se para outra UF ou para o exterior. A maioria dos deslocamentos no país teve como justificativa o exercício profissional, enquanto a maior parte dos que foram para o exterior buscava complementar sua formação. De cada dez afastamentos intrapaís, seis tiveram como motivação o trabalho e quatro a busca de complementação na formação. De cada dez afastamentos para o exterior, 2,5 ocorreram por conta de trabalho, enquanto 7,5 visavam complementar sua formação.

\section{PERFIL DOS AFASTAMENTOS SEGUNDO O LOCAL DA PARTIDA}

Se o destino dos afastados foi informado diretamente pelos respondentes, o local de origem do afastamento é apenas uma proxi da real. Para computarmos os dados pertinentes a esta questão, assumimos que todos os afastamentos mencionados por um respondente foram oriundos da UF de onde o informante respondeu ao questionário (o local de seu endereço eletrônico). No entanto, se perguntarmos por afastamentos no grupo de pesquisa dos respondentes durante um certo número de anos, não há garantia de que a UF ou mesmo a região geográfica serão constantes ao longo do período. O informante, no momento em que respondeu ao questionário, poderia ou não estar no local onde ocorreram os afastamentos que relatou. Pode-se supor, além disso, que, quanto mais antigos os afastamentos descritos, maior a probabilidade de existir incongruência entre a origem geográfica real do afastado e a origem que estamos assumindo como verdadeira.

Mais da metade dos 2.347 afastamentos $(57,6 \%)$ partiu de UFs da região Sudeste, com São Paulo testemunhando o maior deles (722), ou seja, 31\% de todos os afastamentos relatados, sendo responsável também por mais da metade dos afastamentos da região. Além disso, juntamente com o Rio Grande do Sul, foi a única UF que testemunhou mais afastamentos para o exterior do que para outro estado. Os dados referentes aos afastamentos segundo as UFs de onde partiram e seu destino estão na Tabela 5. 
Tabela 5

Afastamentos segundo as UFs de onde Partiram e seu Destino

\begin{tabular}{|c|c|c|c|c|c|c|c|}
\hline \multirow{2}{*}{$\begin{array}{l}\text { UF de } \\
\text { Origem }\end{array}$} & \multirow{2}{*}{$\begin{array}{l}\text { Número de } \\
\text { Afastamentos }\end{array}$} & \multicolumn{2}{|c|}{ Destino Outra UF } & \multicolumn{2}{|c|}{ Destino Outro País } & \multicolumn{2}{|c|}{$\mathrm{NI}\left({ }^{*}\right)$} \\
\hline & & $\mathrm{N}$ & $\%$ & $\mathrm{~N}$ & $\%$ & $\mathrm{~N}$ & $\%$ \\
\hline $\mathrm{SP}$ & 722 & 327 & 45,3 & 386 & 53,5 & 9 & 1,2 \\
\hline RJ & 398 & 220 & 55,3 & 169 & 42,5 & 9 & 2,3 \\
\hline MG & 231 & 150 & 64,9 & 81 & 35,1 & 0 & 0,0 \\
\hline RS & 202 & 96 & 47,5 & 104 & 51,5 & 2 & 1,0 \\
\hline PR & 144 & 100 & 69,4 & 40 & 27,8 & 4 & 2,8 \\
\hline SC & 87 & 54 & 62,1 & 33 & 37,9 & 0 & 0,0 \\
\hline $\mathrm{CE}$ & 74 & 54 & 73,0 & 20 & 27,0 & 0 & 0,0 \\
\hline BA & 68 & 54 & 79,4 & 14 & 25,9 & 0 & 0,0 \\
\hline PA & 53 & 37 & 69,8 & 16 & 30,2 & 0 & 0,0 \\
\hline PB & 51 & 38 & 74,5 & 13 & 34,2 & 0 & 0,0 \\
\hline PE & 50 & 35 & 70,0 & 15 & 30,0 & 0 & 0,0 \\
\hline $\mathrm{DF}$ & 48 & 24 & 50,0 & 24 & 50,0 & 0 & 0,0 \\
\hline GO & 34 & 22 & 64,7 & 10 & 29,4 & 2 & 5,9 \\
\hline $\mathrm{RN}$ & 33 & 20 & 60,6 & 13 & 39,4 & 0 & 0,0 \\
\hline $\mathrm{AM}$ & 25 & 23 & 92,0 & 2 & 8,0 & 0 & 0,0 \\
\hline MT & 16 & 13 & 81,3 & 3 & 18,8 & 0 & 0,0 \\
\hline MS & 16 & 13 & 81,3 & 2 & 12,5 & 1 & 6,3 \\
\hline $\mathrm{AL}$ & 16 & 15 & 93,8 & 1 & 6,3 & 0 & 0,0 \\
\hline ES & 16 & 10 & 62,5 & 5 & 31,3 & 1 & 6,3 \\
\hline SE & 15 & 10 & 66,7 & 5 & 33,3 & 0 & 0,0 \\
\hline MA & 14 & 13 & 92,9 & 1 & 7,1 & 0 & 0,0 \\
\hline PI & 14 & 13 & 92,9 & 1 & 7,1 & 0 & 0,0 \\
\hline $\mathrm{RO}$ & 11 & 10 & 90,9 & 1 & 9,1 & 0 & 0,0 \\
\hline TO & 7 & 6 & 85,7 & 0 & 0,0 & 1 & 14,3 \\
\hline $\mathrm{AC}$ & 2 & 2 & 100,0 & 0 & 0,0 & 0 & 0,0 \\
\hline Total & 2.347 & 1.359 & 57,9 & 959 & 40,9 & 29 & 1,2 \\
\hline
\end{tabular}

(*) Não informado.

Agregando os dados segundo as regiões geográficas e analisando a origem e o destino daqueles que se deslocaram para outra UF, observa-se um padrão que pode ser resumido em: (1) o Sudeste é o destino mais importante em termos numéricos dos oriundos de todas as regiões, inclusive dela própria (afastamentos intra-regionais); (2) os afastamentos ocorridos a partir das regiões Nordeste e Sul tiveram 
como segundo destino mais importante UFs pertencentes a elas mesmas, sendo que mais de $80 \%$ de seus afastamentos se destinaram ao Sudeste ou foram afastamentos intra-regionais; (3) as regiões Norte e Centro-Oeste, além de UFs da própria região, tiveram as regiões Sul e Sudeste como principais destinos (ver Tabela 6).

Tabela 6

Origem e Destino dos Afastamentos entre UFs segundo as Regiões Geográficas

\begin{tabular}{l|c|c|c|c|c|c}
\hline \multirow{2}{*}{$\begin{array}{l}\text { Região de } \\
\text { Origem }\end{array}$} & \multicolumn{7}{|c}{ Região de Destino (\%) } \\
\cline { 2 - 7 } & Sudeste & Sul & Nordeste & Centro-Oeste & Norte & Total \\
\hline Sudeste & 40,8 & 20,8 & 20,3 & 11,8 & 6,2 & 100,0 \\
Sul & 51,0 & 33,1 & 7,5 & 6,7 & 1,7 & 100,0 \\
Nordeste & 51,7 & 8,4 & 30,0 & 4,6 & 5,3 & 100,0 \\
Centro-Oeste & 56,9 & 18,1 & 6,9 & 13,9 & 4,2 & 100,0 \\
Norte & 45,9 & 14,9 & 10,8 & 9,5 & 18,9 & 100,0 \\
\hline
\end{tabular}

Ao desagregarmos os dados da Tabela 6 para subconjuntos referentes ao motivo do afastamento, verifica-se, em primeiro lugar, que a "preferência" geral pela região Sudeste é, basicamente, daqueles que se afastam para complementar sua formação, variando as proporções de afastamento para essa região de $63,2 \%$ entre os que se afastaram da região Norte a $84,2 \%$ entre os oriundos do Centro-Oeste. Além disso, os que se afastaram das regiões Sudeste, Nordeste e Centro-Oeste para estudar, tiveram como destino quase que exclusivamente o Sudeste. As regiões Sul e Norte, além de testemunharem afastamentos importantes para o Sudeste, enviaram pesquisadores para o Sul. No caso da região Norte, os dados devem ser acatados com reserva, em virtude do número muito pequeno de ocorrências (38, das quais 24 se afastaram para o Sudeste).

O que se observa entre os pesquisadores que se encaminharam para outras UFs com o objetivo de trabalhar é que a dispersão é muito maior do que a verificada para os que foram estudar. Para a região Sudeste, destino mais importante dos afastamentos de todas as regiões, foram atraídos sempre menos de $30 \%$ dos afastados de cada uma delas, proporção que variou de $16,4 \%$ entre os oriundos do Nordeste a $28,9 \%$ entre os que se afastaram intra-regionalmente (SE - SE). Aliás, o destino preferencial dos afastamentos com objetivos laborais foi sempre a própria região, chegando a representar $58,2 \%$ entre os que se afastaram de uma UF da região Nordeste. A região Centro-Oeste pos- 
sui um padrão algo distinto, enviando pesquisadores em proporções parecidas para as regiões Sul e Sudeste, além dos afastamentos intra-regionais.

Um outro aspecto a explorar diz respeito à distribuição dos afastamentos intrapaís e no exterior segundo as regiões geográficas de origem. O que se observa é um gradiente proporcional decrescente de afastamentos para o exterior segundo se caminha do "centro" para a "periferia" científica do país. Há, no entanto, uma turbulência nessa tendência, que é o fato de a proporção de afastamentos para o exterior oriunda do Centro-Oeste ser maior do que aquela oriunda da região Nordeste. Se considerarmos que o "mercado" de afastamentos para o exterior se tornou mais e mais restritivo durante a década de 90, pelo menos para a complementação da formação acadêmica, essa maior freqüência de afastamentos para o exterior tendo como origem o Centro-Oeste se deve especificamente ao Distrito Federal. Brasília costuma competir em melhores condições pelas bolsas e auxílios, seja pela qualidade de uma das instituições ali sediada, seja pela proximidade físico-política com o Ministério da Ciência e Tecnologia e com as duas agências de fomento federais ali localizadas 5 . Os dados estão na Tabela 7.

Tabela 7

Origem e Destino dos Afastamentos entre UFs e para o Exterior segundo Regiões Geográficas

\begin{tabular}{l|c|c|c}
\hline \multirow{2}{*}{ Região de Origem } & \multicolumn{3}{|c}{ Destino } \\
\cline { 2 - 4 } & Exterior & Outra UF & Total \\
\hline Sudeste & 47,6 & 52,4 & $\mathbf{1 0 0 , 0}$ \\
Sul & 41,3 & 58,7 & $\mathbf{1 0 0 , 0}$ \\
Centro-Oeste & 35,1 & 64,9 & $\mathbf{1 0 0 , 0}$ \\
Nordeste & 25,1 & 74,9 & $\mathbf{1 0 0 , 0}$ \\
Norte & 19,6 & 80,4 & $\mathbf{1 0 0 , 0}$ \\
\hline
\end{tabular}

Como já foi observado anteriormente, entre os que se ausentaram para estudar, a maioria destinou-se ao exterior, enquanto entre os que se afastaram para trabalhar, a maior parte decidiu-se por outra UF, mais precisamente pela região Sudeste. A única região que testemu- 
nhou mais afastamentos de pesquisadores para o exterior do que para outra UF com a intenção de estudar foi a Sudeste. Na região Sul, os afastamentos com este intuito foram em número praticamente idêntico, para o exterior e para outra UF. Nas demais regiões, a proporção dos que se afastaram para estudar em outra UF foi sempre maior do que a dos que foram para o exterior. Finalmente, a grande maioria dos afastamentos laborais, em todas as regiões de origem, teve como destino outra UF. No entanto, aqui também se observa um gradiente proporcional decrescente para o exterior quando nos deslocamos do "centro" para a "periferia". Dentre os afastamentos procedentes do Sudeste, $26 \%$ destinaram-se ao exterior; dentre os provenientes da região Norte, apenas 5\% tiveram esse destino.

\section{O MOVIMENTO DE RETORNO DOS AFASTADOS}

No final do período de referência (dezembro de 1999), 747 pesquisadores (32,2\%), dentre os $2.318^{6}$ afastados, já haviam retornado ao seu local de origem; $1.484(64,0 \%)$ ainda não haviam regressado e não existia informação sobre a volta de 87 deles (3,8\%).

Para firmar um diagnóstico de afastamento permanente, foi necessário discriminar, entre os que até então não haviam retornado, aqueles que ainda poderiam regressar daqueles de quem não se espera mais o retorno. Dada a complexidade dos fatores envolvidos na decisão de afastar-se, bem como na de retornar ou não, qualquer procedimento discriminante será uma proxi do que virá a ocorrer efetivamente. Naturalmente, a melhor aproximação seria obtida através de entrevistas com os 1.484 pesquisadores que não retornaram até o final de 1999 sobre suas perspectivas, hoje, a respeito de um futuro retorno. No entanto, esse procedimento estava fora das possibilidades do trabalho, e a alternativa metodológica escolhida foi, então, solicitar a opinião subjetiva do informante sobre um eventual retorno do pesquisador afastado.

Com relação àqueles que não haviam retornado até dezembro de 1999, a pergunta feita aos informantes foi: “Em sua opinião, fulano(a) pode ser considerado(a), hoje em dia, como um pesquisador emigrado?" (Sim, Não, Justificar). Com este procedimento, obtivemos o seguinte quadro geral de afastamentos, retornos, prováveis retornos e prováveis não-retornos (migrações) segundo os anos calendário de afastamento (Tabela 8). 
Tabela 8

Afastamentos e Retornos por Situação de Afastamento, e segundo o Tempo de Retorno (Ano do Afastamento)

\begin{tabular}{l|cc|cc|cc|cc|cc}
\hline $\begin{array}{l}\text { Ano do } \\
\text { Afastamento }\end{array}$ & Afastados & \multicolumn{2}{|c|}{ Retornados } & \multicolumn{2}{|c|}{$\begin{array}{c}\text { Retornarão } \\
(*)\end{array}$} & \multicolumn{2}{|c|}{$\begin{array}{c}\text { Não } \\
\text { Retornarão } \\
(*)\end{array}$} & \multicolumn{2}{c}{$\begin{array}{c}\text { Retorno } \\
\text { Ignorado }\end{array}$} \\
\cline { 2 - 11 } & $\mathrm{N}$ & $\%$ & $\mathrm{~N}$ & $\%$ & $\mathrm{~N}$ & $\%$ & $\mathrm{~N}$ & $\%$ & $\mathrm{~N}$ & $\%$ \\
\hline $1993-95$ & 747 & $(100,0)$ & 349 & $(46,7)$ & 110 & $(14,7)$ & 261 & $(34,9)$ & 27 & $(3,6)$ \\
$1996-97$ & 597 & $(100,0)$ & 192 & $(32,2)$ & 140 & $(23,4)$ & 240 & $(40,2)$ & 25 & $(4,2)$ \\
$1998-99$ & 846 & $(100,0)$ & 159 & $(18,8)$ & 307 & $(36,3)$ & 351 & $(41,5)$ & 29 & $(3,4)$ \\
Ano ignorado & 128 & $(100,0)$ & 47 & $(36,7)$ & 23 & $(18,0)$ & 52 & $(40,6)$ & 6 & $(4,7)$ \\
\hline Total & $\mathbf{2 . 3 1 8}$ & $\mathbf{( 1 0 0 , 0 )}$ & $\mathbf{7 4 7}$ & $\mathbf{( 3 2 , 2 )}$ & $\mathbf{5 8 0}$ & $\mathbf{( 2 5 , 0 )}$ & $\mathbf{9 0 4}$ & $\mathbf{( 3 9 , 0 )}$ & $\mathbf{8 7}$ & $\mathbf{( 3 , 7 )}$ \\
\hline
\end{tabular}

${ }^{*}$ ) Retornarão ou não retornarão na opinião subjetiva do informante.

Da tabela podem ser extraídas três evidências: (1) a proporção de retornados é proporcional ao tempo de afastamento; (2) a proporção de não retornados que ainda retornarão é inversamente proporcional ao tempo de afastamento; (3) a proporção de migrantes é relativamente invariante em face do tempo de afastamento, apresentando, no entanto, uma tendência a aumentar em uma proporção inversa a este tempo.

Esse padrão se sustenta quando os dados são desagregados segundo o destino dos afastamentos, se para outra UF ou outro país. A principal diferença está em que entre os que foram para o exterior a proporção de retornados somada à dos que ainda retornarão é bem mais alta $(69,3 \%)$ do que o número correspondente entre os que se afastaram para outra UF (48,7\%). Em conseqüência, a porcentagem dos migrantes entre os primeiros é bem mais baixa $(27,7 \%)$ do que entre os que se moveram dentro do país $(46,9 \%)$.

No que se refere ao padrão de retorno segundo o destino geográfico, especificamente para os afastamentos intrapaís, observa-se uma menor proporção de pesquisadores que não retornarão às UFs de origem entre os que se afastaram para a região Sudeste $(40,7 \%)$. Assim, dos que se dirigiram para SP, apenas $36,7 \%$ não voltarão à UF de origem. Os números correspondentes para o RJ e MG são, respectivamente, $46,5 \%$ e $46,2 \%$. Todas as demais regiões apresentam um percentual de não-retorno acima de 50\%. Como veremos adiante, essa tendência deve estar vinculada, em parte, ao fato de o móvel do deslocamento (formação ou exercício profissional) possuir um padrão distinto entre o "centro" e a "periferia" geográficos. Os dados estão na Tabela 9. 
A Diáspora: Um Estudo Exploratório sobre o Deslocamento Geográfico...

Tabela 9

Perfil dos Afastamentos e Retornos segundo as Regiões de Destino

\begin{tabular}{l|cc|cc|cc|cc|cc}
\hline \multirow{2}{*}{$\begin{array}{l}\text { Região } \\
\text { de Destino }\end{array}$} & \multicolumn{2}{|c|}{ Afastados } & \multicolumn{2}{|c|}{ Retornados } & \multicolumn{2}{|c|}{$\begin{array}{c}\text { Retornarão } \\
(*)\end{array}$} & \multicolumn{2}{c|}{$\begin{array}{c}\text { Não Retor- } \\
\text { narão }\left(^{*}\right)\end{array}$} & \multicolumn{2}{c}{$\begin{array}{c}\text { Retorno } \\
\text { Ignorado }\end{array}$} \\
\cline { 2 - 12 } & $\mathrm{N}$ & $\%$ & $\mathrm{~N}$ & $\%$ & $\mathrm{~N}$ & $\%$ & $\mathrm{~N}$ & $\%$ & $\mathrm{~N}$ & $\%$ \\
\hline Sudeste & 626 & $(100,0)$ & 170 & $(27,2)$ & 172 & $(27,5)$ & 255 & $(40,7)$ & 29 & $(4,6)$ \\
Sul & 269 & $(100,0)$ & 46 & $(17,1)$ & 73 & $(27,1)$ & 145 & $(53,9)$ & 5 & $(1,9)$ \\
Nordeste & 252 & $(100,0)$ & 50 & $(19,8)$ & 60 & $(23,8)$ & 127 & $(50,4)$ & 15 & $(5,9)$ \\
Norte & 77 & $(100,0)$ & 17 & $(22,1)$ & 15 & $(19,5)$ & 42 & $(54,5)$ & 3 & $(3,9)$ \\
Centro-Oeste & 127 & $(100,0)$ & 16 & $(12,6)$ & 40 & $(31,5)$ & 68 & $(53,5)$ & 3 & $(2,4)$ \\
Ignorado & 8 & $(100,0)$ & 2 & $(25,0)$ & 1 & $(12,5)$ & 1 & $(12,5)$ & 4 & $(50,0)$ \\
\hline Total & $\mathbf{1 . 3 5 9}$ & $\mathbf{( 1 0 0 , 0 )}$ & $\mathbf{3 0 1}$ & $\mathbf{( 2 2 , 1 )}$ & $\mathbf{3 6 1}$ & $\mathbf{( 2 6 , 6 )}$ & $\mathbf{6 3 8}$ & $\mathbf{( 4 6 , 9 )}$ & $\mathbf{5 9}$ & $\mathbf{( 4 , 3 )}$ \\
\hline
\end{tabular}

(*) Retornarão ou não retornarão na opinião subjetiva do informante.

Quanto aos afastamentos para o exterior, observa-se que, dentre os que foram para o Canadá, países da América Latina, países asiáticos e Estados Unidos, $30 \%$ ou mais não voltarão ao país - em um patamar superior encontra-se o Canadá, com 40,6\%; os demais países se situam entre $30,0 \%$ e 35,0\%. A este grupo poderia ser adicionado o conjunto "outros países europeus", com 29,7\%. Alemanha, França, Espanha e Reino Unido formam um outro grupo, com taxas entre 23,5\% (Alemanha) e 12,1\% (Espanha) de migrantes. Os dados estão na Tabela 10.

Tabela 10

Perfil dos Afastamentos e Retornos segundo os Países de Destino

\begin{tabular}{l|cc|cc|cc|cc|cc}
\hline País de Destino & Afastados & Retornados & $\begin{array}{c}\text { Retornarão } \\
(*)\end{array}$ & $\begin{array}{c}\text { Não } \\
\text { Retornarão } \\
(*)\end{array}$ & $\begin{array}{c}\text { Retorno } \\
\text { Ignorado }\end{array}$ \\
\cline { 2 - 10 } & $\mathrm{N}$ & $\%$ & $\mathrm{~N}$ & $\%$ & $\mathrm{~N}$ & $\%$ & $\mathrm{~N}$ & $\%$ & $\mathrm{~N}$ & $\%$ \\
\hline Alemanha & 51 & $(100,0)$ & 26 & $(51,0)$ & 12 & $(23,5)$ & 12 & $(23,5)$ & 1 & $(2,0)$ \\
Canadá & 69 & $(100,0)$ & 27 & $(39,1)$ & 12 & $(17,4)$ & 28 & $(40,6)$ & 2 & $(2,9)$ \\
Espanha & 33 & $(100,0)$ & 22 & $(66,7)$ & 7 & $(21,2)$ & 4 & $(12,1)$ & - & - \\
Estados Unidos & 413 & $(100,0)$ & 188 & $(45,5)$ & 86 & $(20,8)$ & 124 & $(30,0)$ & 15 & $(3,6)$ \\
França & 112 & $(100,0)$ & 56 & $(50,0)$ & 30 & $(26,8)$ & 22 & $(19,6)$ & 4 & $(3,6)$ \\
Reino Unido & 111 & $(100,0)$ & 65 & $(58,6)$ & 19 & $(17,1)$ & 25 & $(22,5)$ & 2 & $(1,8)$ \\
Outros Países & & & & & & & & & \\
Europeus & 91 & $(100,0)$ & 41 & $(45,5)$ & 22 & $(24,2)$ & 27 & $(29,7)$ & 1 & $(1,1)$ \\
Países Asiáticos & 33 & $(100,0)$ & 13 & $(39,4)$ & 9 & $(27,3)$ & 10 & $(30,3)$ & 1 & $(3,0)$ \\
América Latina & 40 & $(100,0)$ & 7 & $(17,5)$ & 19 & $(47,5)$ & 14 & $(35,0)$ & - & - \\
Outros/Ignorado & 6 & $(100,0)$ & 1 & $(16,7)$ & 3 & $(50,0)$ & - & - & 2 & $(33,3)$ \\
\hline Total & 959 & $\mathbf{( 1 0 0 , 0 )}$ & $\mathbf{4 4 6}$ & $\mathbf{( 4 6 , 5 )}$ & $\mathbf{2 1 9}$ & $\mathbf{( 2 2 , 8 )}$ & $\mathbf{2 6 6}$ & $\mathbf{( 2 7 , 7 )}$ & $\mathbf{2 8}$ & $\mathbf{( 2 , 9 )}$ \\
\hline
\end{tabular}

$\left(^{*}\right)$ Retornarão ou não retornarão na opinião subjetiva do informante. 
Apresentaremos agora o padrão dos afastamentos e retornos segundo a motivação do afastamento. Como já mostrado, os afastamentos intrapaís tiveram como razão predominante a busca de melhor exercício profissional, enquanto naqueles para o exterior predominou a busca de complementação da formação acadêmica. Quando agregamos os dados relativos ao não-retorno, observamos que a taxa mais baixa de migrantes está entre os que se afastaram para o exterior com objetivos de formação (20,3\%). Em seguida ( $27,1 \%$ de não-retornos "definitivos") estão os que foram para outra UF com o mesmo objetivo. As porcentagens de migração para os que se afastaram por motivos profissionais são bem mais altas - para os que foram para outro país, foi de $48,6 \%$ e para os que se deslocaram para outra UF, foi de $59,8 \%$ (ver Tabela 11).

Tabela 11

Afastamentos e Migrações por Motivação Predominante para o Afastamento segundo o Destino do Afastamento

\begin{tabular}{l|c|c|c}
\hline $\begin{array}{l}\text { Destino do } \\
\text { Afastamento }\end{array}$ & Formação & Exercício Profissional & Total \\
\hline $\begin{array}{l}\text { Afastaram-se para } \\
\text { outra UF e não }\end{array}$ & $(145 / 535)$ & $(493 / 824)$ & $\mathbf{( 6 3 8 / 1 . 3 5 9 )}$ \\
retornarão & $27,1 \%$ & $59,8 \%$ & $\mathbf{4 6 , 9 \%}$ \\
Afastaram-se para & $(144 / 708)$ & $(122 / 251)$ & $\mathbf{( 2 6 6 / 9 5 9 )}$ \\
outro país e não & $20,3 \%$ & $48,6 \%$ & $\mathbf{2 7 , 7 \%}$ \\
retornarão & & & $\mathbf{( 9 / 2 9 )}$ \\
Destino desconhecido & $(2 / 12)$ & $(7 / 17)$ & $\mathbf{3 1 , 0 \%}$ \\
\hline
\end{tabular}

Nosso próximo passo será desagregar os afastamentos e migrações segundo o motivo do afastamento, primeiro por regiões geográficas. Para os afastamentos intrapaís cuja razão foi acadêmica, apenas as regiões Sudeste e Sul apresentam um número de ocorrências capaz de permitir alguma inferência. Se agregarmos os dados referentes às regiões Norte, Nordeste, Centro-Oeste e Sul, verificaremos que das 124 pessoas que se afastaram de seus estados de origem para ali complementarem sua formação, 27,4\% tornaram-se migrantes. Dos 407 que foram para o Sudeste, $27,3 \%$ converteram-se em migrantes. No que toca àqueles que se afastaram tendo como razão predominante o exercício profissional, os dados mostram com nitidez a existência de dois padrões: um para as regiões Sul e Sudeste, onde em torno de 65\% 
dos que para lá foram se tornaram migrantes; e outro para as demais regiões, onde a porcentagem correspondente é de cerca de $54 \%$.

Analisar os afastamentos para o exterior desagregando os dados segundo o motivo do afastamento oferece dificuldades em função do baixo número de ocorrências para vários países. Para tentar contornar esse obstáculo, agregamos os dados de acordo com os Continentes de destino. Estes apresentam um gradiente proporcional de migrantes similar para os que se afastaram com objetivo acadêmico ou profissional. Nos dois casos, as maiores proporções de migrantes encontram-se entre os que se dirigiram para a América do Norte, em seguida para a Ásia, depois para os que foram para a Europa e, por fim, para os que se encaminharam para a América Latina.

Vejamos, agora, a relação entre o tempo de afastamento, medido pelo ano em que o mesmo se deu, e o motivo predominante do mesmo. Nos afastamentos com razões acadêmicas, a proporção de retornados ao final do período de observação aumenta com o tempo de afastamento; já o número dos que ainda retornarão apresenta comportamento oposto (varia inversamente ao tempo de afastamento); a porção dos migrados é relativamente invariante com o tempo de afastamento. Os dados estão na Tabela 12.

Tabela 12

Afastamentos para Complementação da Formação Acadêmica e Retornos, por Situação de Afastamento e o Tempo de Retorno (Ano do Afastamento)

\begin{tabular}{l|cc|cc|cc|cc|cc}
\hline $\begin{array}{l}\text { Ano do } \\
\text { Afastamento }\end{array}$ & Afastados & Retornados & \multicolumn{2}{|c|}{$\begin{array}{c}\text { Retorna- } \\
\left.\text { rão( }{ }^{*}\right)\end{array}$} & \multicolumn{2}{|c|}{$\begin{array}{c}\text { Não } \\
\text { Retornarão } \\
(*)\end{array}$} & \multicolumn{2}{c}{$\begin{array}{c}\text { Retorno } \\
\text { Ignorado }\end{array}$} \\
\cline { 2 - 11 } & $\mathrm{N}$ & $\%$ & $\mathrm{~N}$ & $\%$ & $\mathrm{~N}$ & $\%$ & $\mathrm{~N}$ & $\%$ & $\mathrm{~N}$ & $\%$ \\
\hline $1993-95$ & 456 & $(100,0)$ & 294 & $(64,5)$ & 46 & $(10,1)$ & 105 & $(23,0)$ & 11 & $(2,4)$ \\
$1996-97$ & 308 & $(100,0)$ & 144 & $(46,7)$ & 81 & $(26,3)$ & 68 & $(22,1)$ & 15 & $(4,9)$ \\
$1998-99$ & 409 & $(100,0)$ & 97 & $(23,7)$ & 204 & $(49,9)$ & 95 & $(23,2)$ & 13 & $(3,2)$ \\
Ano ignorado & 82 & $(100,0)$ & 44 & $(53,7)$ & 13 & $(15,8)$ & 23 & $(28,0)$ & 2 & $(2,4)$ \\
\hline Total & $\mathbf{1 . 2 5 5}$ & $\mathbf{( 1 0 0 , 0 )}$ & $\mathbf{5 7 9}$ & $\mathbf{( 4 6 , 1 )}$ & $\mathbf{3 4 4}$ & $\mathbf{( 2 7 , 4 )}$ & $\mathbf{2 9 1}$ & $\mathbf{( 2 3 , 2 )}$ & $\mathbf{4 1}$ & $\mathbf{( 3 , 3 )}$ \\
\hline
\end{tabular}

(*) Retornarão ou não retornarão na opinião subjetiva do informante.

Para os afastados cuja motivação predominante foi o exercício profissional, a tendência é similar à observada entre os que se afastaram para estudar. No entanto, há duas especificidades. Em primeiro lugar, os gradientes de variação das proporções de retornados e daque- 
les que ainda retornarão, em relação ao tempo de afastamento, são muito mais suaves. No caso dos que ainda não retornaram, mas retornarão, um gradiente não chega a se configurar inteiramente. Em segundo lugar, como já mostrado (Tabela 11), as porcentagens de migrantes entre os que se afastaram para trabalhar são bastante altas e variam inversamente ao tempo de afastamento (ver Tabela 13).

Tabela 13

Afastamentos para Exercício Profissional e Retornos, por Situação de Afastamento e o Tempo de Retorno (Ano do Afastamento)

\begin{tabular}{l|cc|cc|cc|cc|cc}
\hline \multirow{2}{*}{$\begin{array}{l}\text { Ano do } \\
\text { Afastamento }\end{array}$} & \multicolumn{2}{|c|}{ Afastados } & \multicolumn{2}{|c|}{ Retornados } & \multicolumn{2}{c|}{$\begin{array}{c}\text { Retorna- } \\
\text { rão(*) }\end{array}$} & \multicolumn{2}{c|}{$\begin{array}{c}\text { Não Retor- } \\
\text { narão(*) }\end{array}$} & \multicolumn{2}{c}{$\begin{array}{c}\text { Retorno } \\
\text { Ignorado }\end{array}$} \\
\cline { 2 - 12 } & $\mathrm{N}$ & $\%$ & $\mathrm{~N}$ & $\%$ & $\mathrm{~N}$ & $\%$ & $\mathrm{~N}$ & $\%$ & $\mathrm{~N}$ & $\%$ \\
\hline $1993-95$ & 299 & $(100,0)$ & 58 & $(19,4)$ & 65 & $(21,7)$ & 157 & $(52,5)$ & 19 & $(6,3)$ \\
$1996-97$ & 295 & $(100,0)$ & 48 & $(16,3)$ & 59 & $(20,0)$ & 174 & $(59,0)$ & 14 & $(4,7)$ \\
$1998-99$ & 446 & $(100,0)$ & 65 & $(14,6)$ & 104 & $(23,3)$ & 259 & $(58,1)$ & 18 & $(4,0)$ \\
Ano ignorado & 52 & $(100,0)$ & 5 & $(9,6)$ & 11 & $(21,1)$ & 31 & $(59,6)$ & 5 & $(9,6)$ \\
\hline Total & $\mathbf{1 . 0 9 2}$ & $\mathbf{( 1 0 0 , 0 )}$ & $\mathbf{1 7 6}$ & $\mathbf{( 1 6 , 1 )}$ & $\mathbf{2 3 9}$ & $\mathbf{( 2 1 , 9 )}$ & $\mathbf{6 2 1}$ & $\mathbf{( 5 6 , 9 )}$ & $\mathbf{5 6}$ & $\mathbf{( 5 , 1 )}$ \\
\hline
\end{tabular}

(*) Retornarão ou não retornarão na opinião subjetiva do informante.

\section{DISCUSSÃO}

A prática do afastamento (residir em outra UF ou outro país) foi um evento razoavelmente presente na vida do pesquisador brasileiro durante a década de 90 . Do total de respondentes, 41,5\% testemunharam o afastamento de participantes de seus grupos de pesquisa que foram viver em outro estado ou no exterior no período de 1993 a 2000.

Cada respondente relatou, em média, o afastamento de 2,2 pessoas, num total de 2.508 pessoas afastadas. Expandindo este número para o total de líderes (10.055), alcançamos um valor aproximado de 1.300 afastados-ano ${ }^{7}$ ou cerca de 9.100 afastamentos no período de referência, de um universo de 50.000 pesquisadores e 13.000 estudantes de doutorado ${ }^{8}$ no ano 2000.

O interesse básico em estimar a movimentação e as perdas de pesquisadores dentro do país (entre unidades da federação) e entre países tem como pressuposto que este último fenômeno é prejudicial à sociedade e à economia dos países que os perdem e que, quanto maiores as defecções, maiores os prejuízos. Dessa perspectiva, talvez a melhor estimativa da ordem de grandeza e do impacto das perdas venha a ser 
a comparação entre estas e a capacidade do país para formar novos pesquisadores. Além de conceitualmente justificada, essa proposta é metodologicamente adequada, pois se trata de uma confrontação entre duas medidas de fluxo. Para tanto, optamos por lançar mão do indicador-padrão dessa capacidade, que é o número anual de egressos do doutorado, fornecido pela CAPES para aqueles que se titularam no país e no exterior.

Estudo recente sobre os doutores ativos em pesquisa no país (Guimarães et alii, 2001b) mostra que, dentre os que obtiveram seus títulos na década de $90,78 \%$ o fizeram no Brasil. Os titulados em programas brasileiros entre 1993 e 1999, de acordo com a CAPES, somam 21.837, valor que, acrescido daqueles que se doutoraram no exterior, alcança aproximadamente 27.300 doutores. Destacando deste último número os $67 \%$ que se dedicam à pesquisa, encontramos 18.291 egressos de doutorado entre 1993 e 1999 que se encaminharam para atividades de pesquisa científica e tecnológica. Dividindo-se este número por sete (anos), temos o número médio anual de egressos (2.613) destinados à pesquisa no Brasil durante o período de referência de nosso estudo.

Os afastados não são apenas candidatos a cursos de doutorado ou recém-doutores. Muitos deles são pesquisadores já maduros que se transferiram com o objetivo de melhor exercer sua profissão. Outros afastados são candidatos a pesquisadores que saíram para doutorar-se. Portanto, a comparação entre o número de pessoas que se afastaram e a capacidade de o país repor seu estoque de pesquisadores doutores é apenas um cotejamento da ordem de grandeza de dois fenômenos que não são perfeitamente superponíveis. Caso a "perda" de parte dessas pessoas que se afastaram, na condição de migrantes para o exterior, seja relevante, poderemos então ter uma proxi da perda por migração em relação à capacidade do país de produzir novos pesquisadores.

A ocorrência dos afastamentos, ou pelo menos a sua lembrança, foi crescente ao longo do período estudado. Além disso, a proporção de pesquisadores migrados apresentou uma pequena, mas consistente, variação inversa ao tempo de afastamento ${ }^{9}$. Em outros termos, pesquisadores que se afastaram entre 1993 e 1995 tornaram-se migrantes em proporção menor do que os que o fizeram em 1998-99. Tais evidências sugerem um crescimento da migração interestadual e internacional de pesquisadores ao longo do período em observação. 
A intensidade dos afastamentos segundo as grandes áreas do conhecimento não é proporcional à quantidade de pesquisadores em atividade no Brasil e parece variar com o grau de internacionalização da pesquisa nas diferentes grandes áreas. As ciências exatas e da Terra e as ciências biológicas foram aquelas em que os afastamentos foram mais freqüentes. No outro extremo, aparecem as ciências sociais aplicadas e a lingüística, letras e artes. Esta hierarquia é, aliás, bastante similar à que se observa entre os pesquisadores estrangeiros em atividade no Brasil. Neste caso, também são as ciências exatas e as biológicas que atraem mais pesquisadores, o que pode ser observado na Tabela 14. Portanto, tudo indica que os estímulos para a mobilização geográfica, no que diz respeito aos diferenciais interáreas, respondem mais a características internas e estruturais das áreas do que a fatores externos ou de ordem conjuntural.

Tabela 14

Pesquisadores Estrangeiros em Atividade no Brasil (2000), Pesquisadores Afastados para outra UF ou para o Exterior (1993-1999) e Pesquisadores Ativos no País (2000) segundo a Grande Área de Atuação (1993-1999)

$(\%)$

\begin{tabular}{l|c|c|c}
\hline Grande Área de Atuação & $\begin{array}{c}\text { Pesquisadores Estran- } \\
\text { geiros no Brasil }\end{array}$ & Afastados & $\begin{array}{c}\text { Pesquisado- } \\
\text { res Ativos } \\
\text { no Brasil }\end{array}$ \\
\hline Ciências Exatas e da Terra & 29,8 & 21,8 & 13,7 \\
Ciências Biológicas & 15,8 & 20,9 & 13,1 \\
Engenharias e C. da Computação & 15,8 & 17,3 & 15,4 \\
Ciências Humanas & 14,3 & 12,3 & 13,0 \\
Ciências Agrárias & 7,4 & 11,3 & 16,1 \\
Ciências da Saúde & 6,3 & 9,5 & 16,0 \\
Ciências Sociais Aplicadas & 5,9 & 4,8 & 8,3 \\
Lingüística, Letras e Artes & 4,8 & 2,0 & 4,2 \\
\hline Total & $\mathbf{1 0 0 , 0}$ & $\mathbf{1 0 0 , 0}$ & $\mathbf{1 0 0 , 0}$ \\
\hline
\end{tabular}

Fonte: CNPq/Diretório dos Grupos de Pesquisa no Brasil (2000) para pesquisadores estrangeiros e total de pesquisadores ativos.

Dos que se afastaram para destino conhecido, 58,6\% (1.359) foram para outra unidade da federação. São Paulo acolheu 26,9\% desse total, enquanto Minas Gerais e Paraná outros 23,0\%. Agregando-se a estes o Rio de Janeiro, Santa Catarina e Rio Grande do Sul, temos as UFs de destino de dois terços dos que se afastaram. Isto confirma a tradi- 
ção das regiões Sudeste e Sul como atraidoras de mão-de-obra de vários níveis de qualificação, além de nelas estar localizada a maior e melhor parte da competência científico-tecnológica do país. Cabe ressaltar, igualmente, a posição relativa dos Estados do Paraná e de Santa Catarina, o primeiro atraindo mais pesquisadores do que o Rio de Janeiro e o segundo mais pesquisadores do que o Rio Grande do Sul. O fato de Curitiba e Florianópolis, bem como algumas outras cidades dos dois estados, serem reconhecidamente detentoras de padrões elevados de qualidade de vida, poderíamos localizar nesta característica um dos estímulos importantes para a movimentação geográfica de pesquisadores dentro do país. Reforça a hipótese o fato de aqueles dois estados possuírem tradição científica menor do que o Rio de Janeiro e o Rio Grande do Sul. Em suma, o que os dados sugerem é que há dois vetores importantes envolvidos nos deslocamentos de longo prazo de pesquisadores entre unidades da federação: o primeiro, relativo às condições específicas do trabalho; o segundo, ao ambiente extratrabalho. Aquele, homenageando a tradição e a competência científico-tecnológica; este, a qualidade de vida em geral.

Dentre as UFs de maior tradição científico-tecnológica, o Rio Grande do Sul e, principalmente, o Rio de Janeiro merecem um olhar especial quanto ao padrão de mobilidade dos pesquisadores durante os anos 90. Em ambas, o "saldo" de pesquisadores que para lá se dirigiram e que de lá se afastaram no período em estudo é amplamente negativo, ao contrário do observado para São Paulo (muito positivo) e Minas Gerais (equilibrado). Na amostra, chegaram ao Rio de Janeiro 114 e saíram 220 pesquisadores. Os que chegaram dividiram-se igualmente entre os que tinham objetivos predominantes de trabalho e de estudo, enquanto entre os que se afastaram, mais de $70 \%$ fizeram-no para trabalhar em outro lugar.

A região Sudeste, além de ter sido o principal destino dos que se afastaram, foi também a principal origem dos mesmos, com mais da metade de todos os afastamentos observados. Neste último aspecto, merece registro a participação de São Paulo, estado de origem de mais da metade dos afastamentos da região e de $31 \%$ de todos aqueles referidos na amostra.

Os afastamentos ocorridos a partir das regiões Nordeste e Sul tiveram como segundo destino mais importante UFs pertencentes a elas mesmas, sendo que mais de $80 \%$ deles se destinaram ao Sudeste ou se ca- 
racterizaram como intra-regionais. Deve ser registrada a importância destes últimos, seja para o exercício da profissão seja para a formação pós-graduada. Pode-se prever que, a continuar o movimento de descentralização da pós-graduação no país, em breve poderão consolidar-se alguns novos centros atraidores permanentes de pesquisadores, desde que a descentralização seja sustentável e acompanhada do fornecimento dos insumos necessários à atividade de pesquisa.

Os afastamentos que tiveram origem nas regiões Norte e CentroOeste apresentaram uma dispersão maior de destinos, agregando ao Sudeste e a UFs próprias da região, a região Sul. Vínculos estabelecidos entre as regiões Centro-Oeste/Sul e Norte/Sul devem ser mais bem estudados, uma vez que podem ser uma decorrência de processos sociais mais amplos de deslocamento de mão-de-obra, com tardias repercussões em seus extratos mais qualificados.

Mais de $90 \%$ dos que se endereçaram para outra UF e cujo destino institucional era conhecido foram para uma instituição de ensino e pesquisa. Apenas uma pequena fração se destinou a empresas $(5,6 \%)$ ou órgãos de governo (1,7\%). A grande maioria foi para a universidade. Esse panorama se ajusta com perfeição ao perfil do parque de pesquisa no Brasil, onde em torno a $90 \%$ da capacidade instalada está localizada em universidades ou institutos de pesquisa.

Dos que se afastaram com destino conhecido, 41,4\% (959) deslocaram-se para outro país. Deste total, quase metade $(43,1 \%)$ foi para os Estados Unidos e outros 23,6\% dividiram-se entre a França e o Reino Unido. Cabe ainda destacar os 7,2\% que se deslocaram para o Canadá. A Europa tomada em conjunto é receptora de uma parcela $(41,5 \%)$ semelhante à dos que foram para os EUA. Este perfil de destino parece corresponder à tradição e intensidade da atividade de pesquisa nos respectivos países e ao padrão histórico de intercâmbio dos pesquisadores brasileiros.

Dentre os que partiram para outro país, os destinos institucionais mostraram-se muito similares àqueles dos que se deslocaram dentro do país. Cerca de $91 \%$ foram para uma universidade ou instituto de pesquisa e os $9 \%$ restantes, para empresas ou órgãos de governo.

A motivação para 1.255 afastamentos $(53,4 \%$ do total) foi a complementação da formação acadêmica, sendo a realização do doutorado a justificativa de quase $60 \%$ deles. Do restante, metade afastou-se para 
fazer pós-doc e a outra metade para realizar outra etapa não especificada de formação. Dentre os que se retiraram para outra UF, a complementação da formação foi o motivo para 39\% dos afastados, enquanto a maioria dos que se encaminharam para o exterior $(74 \%)$ o fizeram com essa justificativa. Para 1.092 afastados (46,6\% do total), a razão alegada foi exercer a profissão ou melhorar o exercício profissional. Dentre os que se dirigiram para outra UF, $61 \%$ tinham essa motivação e dos que foram para o exterior, apenas $26 \%$. Como se vê, há uma diferença nítida com relação às razões do afastamento segundo o destino - se para outra UF ou para o exterior. A razão mais importante para os afastamentos intrapaís está associada ao exercício profissional, e os que foram para o exterior procuravam principalmente a complementação de sua formação acadêmica.

Conforme mencionado, incluímos um pesquisador afastado na categoria de migrado quando o líder de grupo que informou sobre seu afastamento expressou a opinião de que aquela pessoa provavelmente não mais voltaria ao país ou à UF de onde se afastara. Quando desagregamos as várias categorias geradas por esta metodologia - (1) afastados, (2) retornados, (3) não retornados, mas que ainda retornarão e (4) migrados - pelo ano do afastamento (1993-95, 1996, 1997, 1998-99), verificamos um padrão, também já mencionado, que pode ser sintetizado no seguinte: (1) a fração de retornados é proporcional ao tempo de afastamento; (2) a fração de não retornados que ainda retornarão é inversamente proporcional ao tempo de afastamento; (3) a proporção de não retornados que não mais voltarão é relativamente invariante, apresentando uma tendência crescente, inversamente proporcional ao tempo de afastamento. Isto se sustenta tanto para os afastados para outra UF quanto para outro país. Essa distribuição dos pesquisadores migrados segundo o tempo de afastamento leva-nos a refletir sobre uma eventual existência de padrões distintos de afastamento desde a sua origem. Em outras palavras, os informantes opinaram sobre o possível retorno ou não retorno dos afastados independentemente do tempo de cada afastamento e isto pode significar que, em um número muito grande de afastamentos, a decisão de migrar ou retornar já estava tomada desde o início do projeto. Não fora assim, a curva de retorno dos migrados, segundo o ano de afastamento, deveria apresentar-se com um formato parecido com a curva dos já retornados, conforme os modelos expostos no Gráfico 1. 
Gráfico 1

Padrões de Retorno segundo o Tempo de Afastamento (valores fictícios)
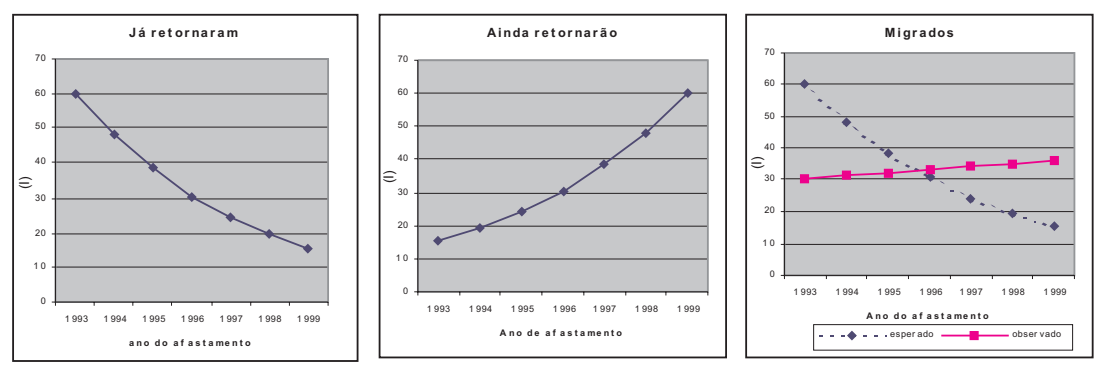

Essa observação é importante porque na literatura sobre o brain drain de pesquisadores do Terceiro Mundo para países do Primeiro é muito ressaltado o modelo de migrante que se afasta com o propósito inicial de retornar (após concluir seu doutorado, na maior parte dos casos) e, por vários tipos de estímulo, termina por permanecer no país receptor. Em outras palavras, nesse modelo, a decisão de migrar seria um processo de sedução cumulativa, contemporânea às condições de vida e trabalho no local de destino. No nosso caso, onde os afastamentos intrapaís jogam um papel igualmente importante, também estaria sob juízo a idéia de que a decisão de migrar seria, em muitas situações, decorrente dos estímulos vivenciados durante um afastamento originalmente planejado para ser temporário. Pelo contrário, o que os nossos dados sugerem é que entre nós, na maioria das vezes, a decisão de migrar já está tomada na raiz do projeto de se afastar.

Essa hipótese é reforçada quando os dados são desagregados levando-se em conta o motivo do afastamento (Gráfico 2). Para os que o fizeram com o objetivo de exercer a profissão, os fatos se passam de modo um pouco diferente do observado entre os que foram estudar os gradientes proporcionais verificados para os que retornaram e para os que ainda retornarão, segundo o tempo de afastamento, são muito suavizados. No entanto, a proporção dos que migraram, além de expressiva, apresenta uma leve tendência inversamente proporcional ao tempo de afastamento. Entre os que se afastaram tendo como meta complementar a formação acadêmica, os gradientes proporcionais entre os retornados e os que ainda vão retornar, segundo o tempo de afastamento, são bem mais nítidos. Além disso, a proporção de mi- 
Gráfico 2
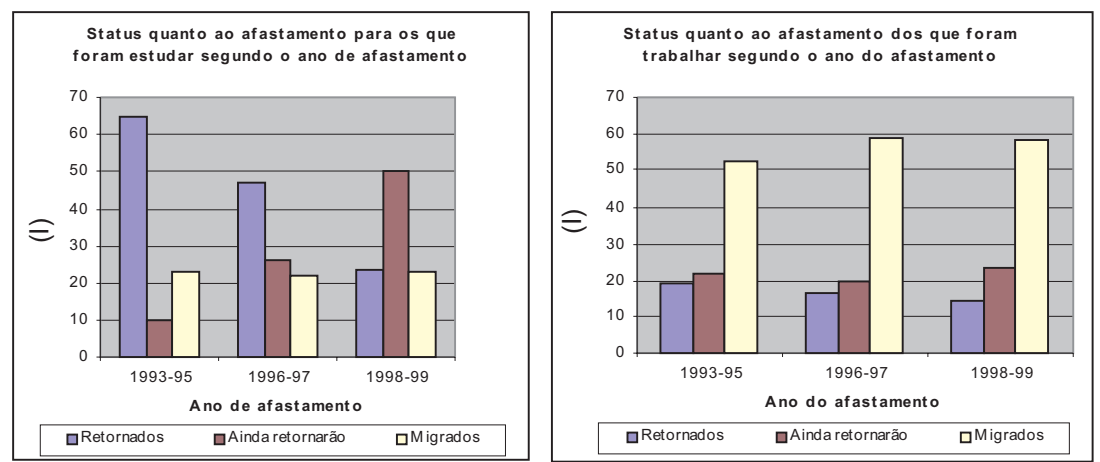

grados, segundo o tempo de afastamento, é praticamente invariante. Isto sugere que, mesmo para os que vão fazer doutorado ou pós-doc em outra UF ou outro país, a decisão de migrar, em muitos casos, pode já estar dada no momento da partida.

Os números da migração intrapaís, segundo o destino geográfico, mostram que a região Sudeste "devolve" à origem, em maior grau do que as demais, os que se deslocaram para ela. A proporção de migrantes entre os que se dirigiram para São Paulo é a menor do país $(36,7 \%$ ), seguida por Minas Gerais e Rio de Janeiro (respectivamente, 46,2\% e $46,5 \%)$. Em todas as demais regiões, os migrantes representam mais de $50 \%$ dos que se encaminharam para elas. Várias razões concorrem para isto. Em primeiro lugar, o fato de os afastamentos no sentido geográfico "periferia-centro" darem-se predominantemente com o objetivo de complementação da formação e, como veremos adiante, os que se afastam com esta finalidade retornam sempre em maior proporção. Em segundo lugar, porque a década de 90 testemunhou uma importante desconcentração geográfica da atividade de pesquisa acadêmica no Brasil (Guimarães et alii, 2001b). Este fato pode ser verificado pelo crescimento do número de programas de doutorado em universidades fora do centro tradicional. Essa desconcentração pode também ter estimulado o retorno de pessoas que se afastaram da periferia geográfica para o centro. Em terceiro lugar, porque é razoável pensar que, no "centro", o mercado de trabalho de pesquisa esteja mais saturado e a competição pelos poucos postos de trabalho disponíveis seja muito mais intensa. Cabe, finalmente, considerar que apesar de o "centro" devolver à "periferia" maior proporção dos que 
para lá se afastaram, pode-se especular que este "centro" faça uma discriminação entre as competências que devolve à origem e as que retém. A investigação desses aspectos qualitativos está além do escopo deste trabalho.

Entre os que se afastaram para o exterior, as maiores taxas de migrantes foram geradas no Canadá (40,6\% de não-retornos) e em outros países da América Latina (35\% de não-retornos). Um segundo patamar de geração proporcional de migrantes inclui os que se dirigiram para os Estados Unidos, para os países asiáticos e para um conjunto de países europeus, à exceção do Reino Unido, França, Alemanha e Espanha. Em cada um dos três conjuntos, a taxa de migrantes foi de aproximadamente $30 \%$. Nos demais países para os quais foram observados afastamentos, as proporções de migrantes são menores (entre $12 \%$ e $23 \%$ dos afastados).

Até agora, discutimos o perfil da migração de pesquisadores através de proporções de migrantes entre afastados segundo o destino geográfico e o motivo predominante desses afastamentos. Essas proporções são, portanto, estimativas de risco de migrar. Em seguida, trataremos de expandir os valores encontrados na amostra para o universo de pesquisadores, representado pelo total de líderes de grupos de pesquisa para os quais foram enviados os questionários. Os números que serão apresentados daqui em diante não mais medem riscos, mas são estimativas do número absoluto de perdas no período em questão. Por vezes, poderão ser observados contrastes importantes entre intensidade de risco e o número absoluto de eventos migratórios que se expressam sob aquela. Por exemplo, já vimos que o país de destino de pesquisadores brasileiros que apresentou a maior taxa de risco de migração durante o período de referência da pesquisa foi o Canadá. Não foi este, no entanto, o país para o qual tivemos mais perdas de pesquisadores, e sim os Estados Unidos. Do ponto de vista da formulação de políticas para tratar o problema da migração, essa diferenciação é importante.

Ao expandirmos para o universo de líderes de grupos de pesquisa os 913 pesquisadores da amostra que estamos considerando migrados, chegamos à conclusão de que 3.314 pesquisadores (474 pesquisadores $\left./ \mathrm{ano}^{10}\right)$, maduros ou em formação, durante o período de sete anos, deixaram sua unidade da federação ou o país para completar sua formação acadêmica ou para trabalhar, e não retornaram à origem. Mais 
ainda, segundo a opinião dos informantes, muito provavelmente não retornarão a essa origem. Repetindo aqui o mesmo exercício de estimação da intensidade do fenômeno - agora realmente migrantes para outra UF ou para outro país - pela comparação com a capacidade brasileira de produzir novos pesquisadores (egressos do doutorado que se dirigem à pesquisa), tivemos uma "perda" de 474 pesquisadores/ano contra um ingresso potencial de 2.613 novos doutores/ano que se dirigiram à pesquisa no período de referência $(18,1 \%)$.

Para os que se deslocaram dentro do país, a região Sudeste foi a maior receptora e as demais regiões "perderam" para ela 926 pesquisadores entre 1993 e 1999 (132 pesquisadores/ano). A região Norte foi a que menos recebeu pesquisadores migrados - 153 (22 pesquisadores/ano). Importa observar que aqui estamos mencionando apenas o que se recebeu, sem levar em conta o que foi "cedido". Além disso, o rótulo de "perda regional" não é preciso, pois muitos migrados para uma determinada UF podem ter sido oriundos de uma outra UF da mesma região. Os dados sobre o número de pesquisadores migrados para todas as regiões estão na Tabela 15.

Tabela 15

Estimativa do Número de Pesquisadores Migrados segundo as Regiões de Destino (amostra expandida)

\begin{tabular}{l|c|c}
\hline Regiões de Destino & Migrados entre 1993 e 1999 & Migrados por Ano \\
\hline Sudeste & 926 & 132 \\
Sul & 527 & 75 \\
Nordeste & 461 & 66 \\
Centro-Oeste & 247 & 35 \\
Norte & 153 & 22 \\
\hline Total & $\mathbf{2 . 3 1 4}$ & 330 \\
\hline
\end{tabular}

Obs.: Excluídos quatro pesquisadores para os quais não se conhecia a região de destino.

Perdas para o país só se aplicam, naturalmente, àqueles que migraram para o exterior, e a proporção destes em relação aos que migraram para outra UF é sensivelmente menor. Entre os últimos, 638 $(46,9 \%)$, de um total de 1.359 pessoas que se afastaram, foram consideradas migrantes. Portanto, cerca de metade dos que se afastaram de sua UF para trabalhar ou complementar sua formação acadêmica não mais voltarão àquela UF. Entre os que foram para o exterior, 
$27,7 \%$ (266) dos 959 afastados foram considerados migrantes pelos informantes. Expandindo a amostra para o universo de líderes, encontramos 138 pesquisadores / ano migrados para o exterior, o que representa 5,3\% de nossa capacidade potencial de ingresso de pesquisadores no período em tela. As estimativas de pesquisadores migrados segundo o país de destino estão na Tabela 16.

Tabela 16

Perdas de Pesquisadores para o Exterior segundo Países ou Conjunto de Países de Destino (amostra expandida)

\begin{tabular}{l|c|c}
\hline País de Destino & Migrados entre 1993 e 1999 & Migrados por Ano \\
\hline Estados Unidos & 450 & 64 \\
Canadá & 102 & 15 \\
Reino Unido & 91 & 13 \\
França & 80 & 12 \\
Outros países europeus & 156 & 22 \\
América Latina & 51 & 7 \\
Ásia & 36 & 5 \\
\hline Total & $\mathbf{9 6 6}$ & $\mathbf{1 3 8}$ \\
\hline
\end{tabular}

Esse perfil de migração segundo os países de destino inclui, possivelmente, três fatores de atração atuando em conjunto ou isoladamente. O primeiro deles é a competência e a liderança na pesquisa, caso dos Estados Unidos e, para algumas áreas do conhecimento, a França e a Grã-Bretanha. O segundo, a expectativa de oportunidades de trabalho e receptividade a estrangeiros, representado pelo Canadá. E o terceiro, expresso por alguns países da América Latina, a proximidade lingüística associada ao prestígio da pesquisa brasileira na região, o que facilitaria a absorção de nossos pesquisadores.

Talvez a maior originalidade do Brasil em termos de pesquisa científica e tecnológica, quando comparado com outros países em desenvolvimento, não tenha sido a construção de um parque científico significativo. Talvez a decisão (ou a resultante) de constituir este parque em paralelo a um sistema de formação de doutores no país, hoje responsável pela formação de mais de $80 \%$ dos mesmos, tenha sido o fato mais original. Mais original ainda se a isto se somar a política de estímulo à formação pós-graduada por intermédio de bolsas de estudo. Apenas para ilustrar a efetividade desta política, temos que, em 1990, $46,2 \%$ dos doutores pesquisadores em ciências naturais na Coréia ti- 
nham obtido seus títulos nos Estados Unidos (Choi, 1999). A porcentagem para o Brasil, em 2000, era de 8,4\% (para todas as áreas do conhecimento) (Guimarães et alii, 2001b). Esses dois fatos, a pós-graduação no país e as bolsas (em particular para os que vão para o exterior), podem informar, em grande parte, sobre o perfil dos pesquisadores migrantes segundo o motivo original do afastamento. Os que optaram por outra UF ou pelo exterior visando poder exercer sua profissão em melhores condições tornaram-se migrantes em uma proporção mais de duas vezes maior do que os que se afastaram para complementar sua formação acadêmica. Entre os primeiros, observamos $57 \%$ de migrantes e nestes últimos apenas $23,2 \%$. O fato de a imensa maioria dos novos doutores (e, estima-se, um número cada vez maior de pós-docs) ser egressa de programas nacionais e de que quase todos os que vão para o exterior cumprir essas etapas de formação serem detentores de bolsas de estudo deve contribuir para que as taxas de migrantes entre os afastados com esse objetivo sejam bem mais baixas do que entre os que se afastaram para trabalhar. Em números absolutos, dos 1.255 afastados com o propósito de completar a formação acadêmica, 291 tornaram-se migrantes. Os números correspondentes para os que foram exercer sua profissão são 1.092 e 622, respectivamente. Estas observações são importantes porque, de modo geral, a literatura sobre a migração de pessoal qualificado, e de pesquisadores em particular, dos países em desenvolvimento para os países centrais considera que a complementação da formação é a rota mais importante para a fixação de cérebros oriundos dos primeiros nestes últimos países (Meyer e Brown, 1999).

Dentre os que se afastaram para outras UFs com o objetivo de estudar, $76 \%$ destinaram-se à região Sudeste. Este fato, decorrente da concentração regional dos programas doutorais e de estágios pós-doutorais, torna imprudente analisar as outras regiões de per si, pelos pequenos números envolvidos. Se agregarmos os dados referentes às regiões Norte, Nordeste, Centro-Oeste e Sul, verificaremos que, das 124 pessoas que se afastaram para ali complementarem sua formação, 34 $(27,4 \%)$ tornaram-se migrantes. Dentre os 407 que foram para o Sudeste, $111(27,3 \%)$ migraram. Nenhuma diferença, o que coloca em tela de juízo a noção comum de que as instituições da região Sudeste retêm parcela significativa dos que para ela se dirigem para complementar sua formação. Os dados sugerem que elas retêm em proporção semelhante às de outras regiões. No entanto, aqui também cabe 
ressaltar a distinção entre a medida de risco e os valores absolutos de migrantes. Embora os riscos sejam similares, o número absoluto de migrantes para o Sudeste é o triplo do observado para as demais regiões, em virtude de aquela região ser o destino de um grande número de afastamentos (ver Tabela 17).

Tabela 17

Estimativa do Número de Pesquisadores Migrados com o Objetivo de Complementar a Formação Acadêmica segundo as Regiões de Destino (amostra expandida)

\begin{tabular}{l|c|c}
\hline Região de Destino & $\begin{array}{c}\text { Migrados entre 1993 e } \\
1999\end{array}$ & Migrados por Ano \\
\hline Sudeste & 403 & 58 \\
Demais regiões & 123 & 18 \\
\hline
\end{tabular}

No que se refere aos afastados para o exercício profissional, observam-se dois níveis na proporção de migrantes. Um mais alto, entre aqueles que se deslocaram para as regiões Sul e Sudeste, com cerca de 65,0\% de migrantes (277 migrantes entre 426 afastados). Outro, mais baixo, para os que foram para outras regiões, com $54,6 \%$ de migração (215 em 394). De qualquer modo, ambas são proporções altas, indicando que o movimento de pesquisadores em busca de melhores condições de trabalho possui maior influência nos padrões de migração interna do que o movimento decorrente da necessidade de complementar a formação acadêmica (ver Tabela 18).

Tabela 18

Estimativa do Número de Pesquisadores Migrados com o Objetivo de Trabalhar segundo as Regiões de Destino

(amostra expandida)

\begin{tabular}{l|c|c}
\hline Região de Destino & Migrados entre 1993 e 1999 & Migrados por Ano \\
\hline Sudeste & 523 & 75 \\
Sul & 483 & 69 \\
Nordeste & 425 & 61 \\
Norte e Centro-Oeste & 356 & 51 \\
\hline
\end{tabular}

Obs.: Excluídos quatro pesquisadores para os quais não se conhecia a região de destino.

Vê-se que, nesse caso, embora o risco de migrar para o Sudeste seja maior, os números absolutos de migrantes para cada uma das regiões são muito mais parelhos. É possível que, no caso de migrações decorrentes de um objetivo primário de trabalho, haja a intervenção de 
múltiplos determinantes, distribuídos entre as diversas regiões. Por exemplo, a maior competitividade do mercado de trabalho no Sudeste ou a qualidade de vida nas cidades médias do Sul e, eventualmente, do Nordeste.

A análise dos migrantes por país de destino segundo o objetivo do afastamento também mostra que a proporção de migrantes entre os que foram estudar $(20,3 \%)$ e os que foram trabalhar $(48,6 \%)$ apresenta um diferencial parecido com o observado para os afastamentos intrapaís. As maiores proporções de migrantes encontram-se entre os que foram para a América do Norte (23,7\% para os que foram estudar e $53,1 \%$ para os que foram trabalhar). Em seguida, para os que se encaminharam para a Europa (respectivamente, 17,0\% e 46,7\%). Os números para a Ásia, América Latina e África são muito pequenos para permitir inferências. De qualquer modo, tudo parece indicar que é para os Estados Unidos, pela competitividade e liderança em pesquisa, e para o Canadá, pela maior possibilidade de absorção e socialização, que olham os pesquisadores brasileiros migrantes potenciais (ver Tabelas 19 e 20).

Tabela 19

Estimativa do Número de Pesquisadores Migrados com o Objetivo de Complementar a Formação segundo os Países de Destino (amostra expandida)

\begin{tabular}{l|c|c}
\hline País de Destino & $\begin{array}{c}\text { Migrados entre 1993 e } \\
1999\end{array}$ & Migrados por Ano \\
\hline América do Norte & 305 & 44 \\
Europa & 200 & 29 \\
Ásia e América Latina & 18 & 3 \\
\hline
\end{tabular}

Tabela 20

Estimativa do Número de Pesquisadores Migrados com o Objetivo de Trabalhar segundo os Países de Destino

(amostra expandida)

\begin{tabular}{l|c|c}
\hline País de Destino & $\begin{array}{c}\text { Migrados entre 1993 e } \\
1999\end{array}$ & Migrados por Ano \\
\hline América do Norte & 247 & 35 \\
Europa & 127 & 18 \\
Ásia e América Latina & 69 & 10 \\
\hline
\end{tabular}


Dos dados das tabelas, vale destacar que a Ásia e a América Latina foram os destinos onde o número de migrados com o objetivo de trabalhar supera os que migraram para estudar.

\section{CONCLUSÕES}

(1) Nesta pesquisa foram trabalhadas três categorias de movimentos que resumimos em seguida: (1) a de afastamento, indicando um pesquisador que, provisória ou definitivamente, foi viver no exterior ou em uma UF diferente da que vivia, então; (2) a de risco de migrar, indicada pela proporção dos afastados que não retornaram à UF de origem e que, provavelmente, não voltarão segundo a opinião dos informantes; (3) a do número absoluto de migrados, que resultou da expansão para o universo de líderes de grupo (10.055) do número de pesquisadores que migraram, a partir do numerador da proporção mencionada em (2). Um quadro-resumo dos números gerais envolvidos nas três categorias é apresentado nas Tabelas 21, 22 e 23.

Tabela 21

Número Absoluto de Afastamentos na Amostra

\begin{tabular}{l|c|c|c}
\hline & Trabalho & Formação & Total \\
\hline Outra UF & 824 & 535 & 1.359 \\
Exterior & 251 & 708 & 959 \\
Destino ignorado & 17 & 12 & 29 \\
\hline Total & $\mathbf{1 . 0 9 2}$ & $\mathbf{1 . 2 5 5}$ & $\mathbf{2 . 3 4 7}$ \\
\hline
\end{tabular}

Tabela 22

Risco de Migração (\%)

\begin{tabular}{l|c|c|c}
\hline & Trabalho & Formação & Total \\
\hline Outra UF & 59,8 & 27,1 & 46,9 \\
Exterior & 48,6 & 20,3 & 27,7 \\
Destino ignorado & 41,2 & 16,7 & 31,0 \\
\hline Total & $\mathbf{5 7 , 0}$ & $\mathbf{2 3 , 2}$ & $\mathbf{3 8 , 9}$ \\
\hline
\end{tabular}


A Diáspora: Um Estudo Exploratório sobre o Deslocamento Geográfico...

Tabela 23

Estimativa do Número de Migrados (1993/1999)

na Amostra Expandida

\begin{tabular}{l|c|c|c}
\hline & Trabalho & Formação & Total \\
\hline Outra UF & 1.790 & 526 & 2.316 \\
Exterior & 443 & 523 & 966 \\
Destino ignorado & 25 & 7 & 32 \\
\hline Total & $\mathbf{2 . 2 5 8}$ & $\mathbf{1 . 0 5 6}$ & $\mathbf{3 . 3 1 4}$ \\
\hline
\end{tabular}

Vale notar que o número estimado de migrados na amostra expandida varia de acordo com as outras duas categorias, isto é, com o número de afastamentos, que é a resultante dos estímulos sofridos pelo pesquisador para viver em outra UF ou no exterior e com a taxa de risco de, lá estando, não mais retornar. Tomando o destino do afastamento e sua motivação predominante, como fazem as tabelas acima, em algumas situações observa-se convergência entre a intensidade do estímulo de se afastar e o risco de não voltar. Assim ocorre, por exemplo, com os afastados para outra UF, cuja razão predominante foi a busca de trabalho. Foram muitos os que se afastaram, sendo estes submetidos a um alto risco de não retornar. Como conseqüência, forneceram o maior número absoluto de migrados. Em outras situações, no entanto, essa convergência deixa de existir, como, por exemplo, entre os que foram para o exterior complementar sua formação acadêmica. Embora muitos tenham se afastado com esta motivação e destino, no período de referência estiveram submetidos a uma baixa taxa de risco de tornarem-se migrantes. Em decorrência disso, forneceram o menor número absoluto de pesquisadores migrados entre os quatro tipos de afastamento exibidos nas tabelas. Aliás, a motivação de complementar a formação, no exterior ou em outra UF, afastou mais pesquisadores do que a motivação de trabalhar. No entanto, as taxas de risco de tornarem-se migrantes entre os primeiros é muito mais baixa do que entre estes últimos. O resultado é que o número estimado de migrantes entre os que foram trabalhar é mais que o dobro do que entre os que foram estudar.

(2) Durante os anos 90, o pesquisador migrante brasileiro mais típico trocou de estado visando melhor exercer sua profissão. Para tanto, dirigiu-se a uma instituição acadêmica do Sudeste ou do Sul do país e, 
na maioria dos casos, a idéia de migrar esteve presente desde o início do projeto. Cerca de 1.000 pesquisadores seguiram essa trajetória entre 1993 e 1999, em média 140 a cada ano. No entanto, as demais regiões geográficas foram também ponto de chegada de um número importante de migrantes, em torno de 780 no período de sete anos ou pouco mais de 100 por ano.

(3) Neste balanço regional, existiram importantes rotas de deslocamento entre duas unidades da federação de uma mesma região. Este fato pode estar ligado ao crescimento de núcleos regionais de atividade científico-tecnológica e de formação de recursos humanos que merece um olhar mais acurado por parte de pesquisadores e formuladores de política.

(4) O número de pesquisadores que migraram para outra UF a partir de um afastamento que visava originalmente complementar sua formação acadêmica no país foi apenas 30\% dos que migraram para trabalhar. Na amostra expandida, foram, respectivamente, 526 contra 1.790, nos sete anos. Cerca de $70 \%$ dos que migraram a partir de um programa original de estudos dirigiram-se a uma instituição na região Sudeste.

(5) A escolha do destino dos migrantes cujo móvel foi o trabalho foi motivada, naturalmente, pela busca de melhores condições de trabalho e/ou salário. No entanto, os dados sugerem que também pode ter sido levada em conta a qualidade de vida nos locais de destino. Essa evidência decorre de termos constatado fluxos intensos para locais com menor tradição científica relativa, como, por exemplo, os Estados de Santa Catarina e Paraná quando comparados com o Rio de Janeiro ou o Rio Grande do Sul. Estes dois últimos merecem, aliás, uma atenção especial, pois apresentam "saldos" negativos importantes quando confrontamos os que migraram a partir deles e os que migraram para eles, dentro do país.

(6) O padrão dos afastamentos (não apenas dos migrantes), segundo a grande área de conhecimento dos pesquisadores, parece obedecer predominantemente a aspectos estruturais e epistemológicos de cada grande área, mais do que a dimensões conjunturais e externas ao trabalho de pesquisa (mercado de trabalho, por exemplo). Os pesquisadores de grandes áreas mais internacionalizadas - ciências exatas e 
ciências biológicas - possuem maior "mobilidade", dentro do país ou para o exterior.

(7) No que se refere ao exterior, 966 pesquisadores migraram no período de referência, com uma média anual de 138. Quase $60 \%$ desse total (552) migrou para os Estados Unidos ou para o Canadá e, destes, a maioria (305) abandonou o país em função de um projeto que envolvia a complementação de sua formação acadêmica, em particular o doutorado. Os que migraram para trabalhar na América do Norte foram 247. O segundo destino dos migrantes brasileiros para o exterior foi a Europa, com $34 \%$ do total de migrantes que deixaram o país.

(8) Há evidências diretas (a descrição de um número crescente de afastamentos segundo o ano, entre 1993 e 1999) e indiretas (o crescimento da proporção de migrantes entre os afastados quanto mais recente tiver sido o afastamento) de que o fenômeno migratório aumentou durante o período de referência. Essas evidências indicam também que o crescimento das migrações se deve mais ao conjunto de pesquisadores que migram para trabalhar e que isto incide quer sobre os migrantes internos quer sobre os internacionais.

(9) A existência de um parque científico significativo instalado no país e, principalmente, o fato de a ele estar acoplado um importante aparelho de formação de doutores coloca o Brasil em uma posição distinta da dos demais países do Terceiro Mundo quanto ao fenômeno da migração de pesquisadores. Diferente da maioria dos países da África e da América Latina, posto que estes, com poucas exceções, não possuem pesquisa própria, e diferente também de países como a Índia e a China que, embora tenham parques de pesquisa relevantes, ainda dependem bastante dos doutorados no exterior para reproduzir sua força de trabalho científico-tecnológica.

(10) Dessa perspectiva, a situação brasileira quanto à diáspora científica parece aproximar-se da do Canadá que, como nós, tem na busca de melhores condições de trabalho e de salário (em particular nos EUA) o maior estímulo para a migração de mão-de-obra qualificada. A provável grande diferença entre o Canadá e o Brasil nessa matéria é que o saldo migratório líquido no Canadá é amplamente favorável ao país (Zao et alii, 2000), enquanto para o Brasil não há dados consolidados sobre o assunto. 
(11) Parece ocioso debater, em abstrato, se a migração de pesquisadores brasileiros para o exterior é ou não, hoje em dia, significativa. Certamente, entre nós não se observa a sangria vivida por muitos países do Terceiro Mundo, como a vizinha Argentina ou como alguns países da África e do Extremo Oriente (Tailândia, por exemplo). E é certo também que, de acordo com nossos números, perdemos para o exterior apenas 5,3 em cada 100 novos pesquisadores doutores colocados no mercado entre 1993 e 1999. No entanto, o problema visto sob outro ângulo, o da contabilidade simples daqueles que migraram, foram 966 pesquisadores que perdemos - ou pelo menos que deixamos de contar em sua plenitude laboral -, o que corresponde à média de 11,5 pesquisadores emigrados a cada um dos 84 meses do período.

(12) Reitera-se o caráter exploratório do estudo e, como conseqüência, a necessidade de pesquisas mais focadas, capazes de conhecer e interpretar mais profundamente aspectos particulares do panorama que tivemos a oportunidade de apresentar. O que nos parece inquestionável é a conclusão de que a mobilidade geográfica de pesquisadores, bem como os processos migratórios externos e internos, apresentam hoje em dia elementos novos e uma complexidade que os poucos estudos tradicionais brasileiros sobre o tema não são suficientes para explicar.

(Recebido para publicação em janeiro de 2002) 


\section{A Diáspora: Um Estudo Exploratório sobre o Deslocamento Geográfico...}

\section{NOTAS}

1. Nesse contexto, o termo pesquisadores equivale à categoria norte-americana de scientists and engineers.

2. Indexação na base de dados do Institute for Scientific Information - ISI. No mesmo período, a produção mundial experimentou crescimento de $30 \%$.

3. “No período de 01/01/1993 a 31/12/1999, algum integrante (pesquisador ou estudante) do grupo de pesquisa do qual você faz (fazia) parte afastou-se do estado onde o grupo está (estava) sediado para residir em outra unidade da federação ou em outro país?"

4. No terreno científico-tecnológico, o Estado do Espírito Santo apresenta características bem mais próximas da região Nordeste do que da região Sudeste, à qual pertence. Em conseqüência deste fato, em todas as tabulações que se seguem, decidimos incluí-lo na região Nordeste.

5. A hipótese é reforçada quando verificamos que dos 39 afastamentos originados do Centro-Oeste para o exterior, $61 \%$ foram oriundos do Distrito Federal. Dos 75 afastamentos para outra UF, apenas $24 \%$ tiveram essa origem.

6. Para 29 afastamentos não se conhecia nem o destino nem a motivação do mesmo. Portanto, dos 2.347 afastados, analisaremos o retorno de 2.318 .

7. $[(2.508 \times 10.055) / 2.769)] / 7=1.301,03$ afastados por ano entre 1993 e 1999.

8. Números aproximados de pesquisadores e estudantes de doutorado diretamente vinculados aos grupos de pesquisa em 2000.

9. Com exceção dos que foram para o exterior com a finalidade de complementar sua formação acadêmica, onde a proporção de migrados segundo o tempo de afastamento é invariante.

10. $[(913 \times 10.055) /(2.769)] / 7=473,6$ pesquisadores migrados por ano entre $1993 \mathrm{e} 1999$. 


\section{REFERÊNCIAS BIBLIOGRÁFICAS}

AMARAL, L. A. N., SCALA, A., BARTHÉLÉMY, M. eSTANLEY, H. E. (2000), “Classes of Small World Networks". Proceedings of the National Academy of Sciences, vol. 97, nํ21.

BRADLEY, N. (1999), “Sampling for Internet Surveys: An Examination of Respondent Selection for Internet Research". Journal of the Market Research Society, vol. 41, nํ⒋

CHOI, H. (1999), "Shifting Human Resources in South Korean Science and Technology". Comparative Education Review, vol. 43, no 2 .

DEPARTMENT OF COMMERCE. (1998), The Emerging Digital Economy. Disponível em: <http://www.ecommerce.gov>.

GUIMARÃES, R., LOURENÇO, R. e COSAC, S. (2001a), O Brasil no ISI. Texto inédito.

__. (2001b), “Os Pesquisadores: Perfil dos Doutores em Pesquisa no Brasil”. Parcerias Estratégicas, no 13, dezembro de 2001.

GWYNNE, P. (1999), Brain Circulation Replacing "Brain Drain" to US: As ForeignBorn Scientists, Engineers Return Home. Disponível em: <http:// www.online journal.net/iri/RTM/1999/42/1/>.

KIESLER, S. e SPROULL, L. S. (1986), "Response Effects in the Electronic Survey". Public Opinion Quarterly, vol. 50, pp. 402-413.

MENEGHINI, R. (1996), “The Key Role of Collaborative Work in the Growth of Brazilian Science in the Last Ten Years". Scientometrics, vol. 35, no 3, pp. 367-373.

MEYER, J. B. e BROWN, M. (1999), Scientific Diasporas: A New Approach to BrainDrain. Trabalho apresentado na World Conference on Science, UNESCO-ICSU, Budapest. Disponível em: <http:// www.unesco.org/most/meyer.htm>.

NEWMANN, M. E. J. (2001), "The Structure of the Scientific Collaboration Networks". Proceedings of the National Academy of Sciences, vol. 98, nำ2.

ONI, B. (2000), Capacity Building Effort and Brain Drain in Nigerian Universities. Trabalho apresentado na Regional Conference on Brain-Drain and Capacity Building in Africa. 2000. Disponível em: <http://www.uneca.org/ecaãresources>.

SASAKI, E. M. (1998), "Dekasseguis: Migrantes Brasileiros no Japão". Anais do XI Encontro Nacional de Estudos Populacionais da ABEP, pp. 577-603.

SCHUSTER, J. H. (1994), “Emigration, Internationalization, and Brain Drain: Propensities among British Academics". Higher Education, ㄲo 28.

SCHWARTZMAN, S. (1972), Projeto Retorno: Avaliação do Impacto do Treinamento no Exterior de Pessoal Qualificado. Relatório Final da Pesquisa, Rio de Janeiro, março. Disponível em: <http://www.airbrasil.org.br/simon/>.

_. (1978), "Brain-Drain: Pesquisa Multinacional?", in E. O. Nunes (org.), A Aventura Sociológica - Objetividade, Paixão, Improviso e Método na Pesquisa Social. Rio de Janeiro, Zahar Editores.

SHEEHAN, K. (2001), “E-mail Survey Responses Rates: A Review”. Journal of Computed Mediated Communication, vol. 6, no 2 . 
e HOY, M. G. (1999), “Using E-mail to Survey Internet Users in the United States: Methodology and Assessment". Journal of Computer Mediated Communication. Disponível em: <http://www.ascusc.org/jcmc/vol3/issue1/smith.html>.

SHEEHAN, K.B. e MCMILLAN, S. J. (1999), “Response Variations in E-mail Surveys: An Exploration". Journal of Advertising Research, vol. 39, nำ4, pp. 45-54.

TEFERRA, D. (2000), Revisiting the Brain Mobility Doctrine in the Informational Age. Trabalho apresentado na Regional Conference on Brain-Drain and Capacity Building in Africa. Disponível em: <http://www.uneca.org/ecaãresources>.

ZAO, J., DREW, D. e MURRAY, T. S. (2000), “Brain Drain and Brain Gain: The Migration of Knowledge Workers from and to Canada". Education Quarterly Review, vol. 6, no3.

\begin{abstract}
The Diaspora: An Exploratory Study on the Geographic Displacement of Brazilian Researchers in the 1990s

This is an exploratory study on geographic displacement patterns among researchers in Brazil during the 1990s. The mobility of researchers has not been studied in Brazil since the 1970s, when the country's demographic panorama was quite different from the present. The results indicate a rather intense migratory pattern, particularly between States of the country, and that the most frequent motive was the search for better work conditions. The Southeast region is the greatest magnet for skilled human resources, and the mobility pattern there is much complex merely than a migratory route from the North and Northeast to Rio de Janeiro and São Paulo. Finally, the data suggest that migration increased during the 1990s and that there was an appreciable brain drain out of the country.
\end{abstract}

Key words: migration; brain drain; scientific diaspora 


\section{RÉSUMÉ}

La Diaspora: Étude Exploratoire du Déplacement Géographique des Chercheurs Brésiliens dans les Années 90

Il s'agit d'une étude exploratoire du modèle de déplacement des chercheurs au Brésil dans les années 1990-2000. La mobilité de ces chercheurs n'y a pas été étudiée depuis les années 70, alors que le panorama démographique du pays était relativement différent de celui d'aujourd'hui. Les résultats montrent un modèle migratoire assez intense, en particulier entre les États brésiliens, le motif le plus fréquent en étant la recherche de meilleures conditions de travail. La région Sud-Est est celle qui attire le plus de ressources humaines qualifiées, et son modèle de mobilité est bien plus complexe que le parcours des migrants venant du Nord et du Nord-Est vers Rio de Janeiro et São Paulo. Les données obtenues suggèrent que la migration a augmenté pendant les années 90 et que les départs à l'étranger ne sont pas à mépriser.

Mots-clé: migration; fuite des cerveaux; diaspora scientifique 